\title{
Immigration and Child Mortality: Lessons from the United States at the Turn of the Twentieth Century
}

\author{
Martin Dribe $^{1}\left(\mathbb{D}\right.$, J. David Hacker ${ }^{2}$ and Francesco Scalone ${ }^{3}$ \\ ${ }^{1}$ Centre for Economic Demography and Department of Economic History, Lund University, ${ }^{2}$ Minnesota \\ Population Center and Department of History, University of Minnesota and ${ }^{3}$ Department of Statistical \\ Sciences, University of Bologna \\ Email: martin.dribe@ekh.lu.se
}

(Received 05 January 2018; revised 01 November 2018; accepted 25 November 2018; first published online 23 January 2020)

\begin{abstract}
The societal integration of immigrants is a great concern in many of today's Western societies, and has been so for a long time. Whether we look at Europe in 2015 or the United States at the turn of the twentieth century, large flows of immigrants pose challenges to receiving societies. While much research has focused on the socioeconomic integration of immigrants there has been less interest in their demographic integration, even though this can tell us as much about the way immigrants fare in their new home country. In this article we study the disparities in infant and child mortality across nativity groups and generations, using new, high-density census data. In addition to describing differentials and trends in child mortality among 14 immigrant groups relative to the native-born white population of native parentage, we focus special attention on the association between child mortality, immigrant assimilation, and the community-level context of where immigrants lived. Our findings indicate substantial nativity differences in child mortality, but also that factors related to the societal integration of immigrants explains a substantial part of these differentials. Our results also point to the importance of spatial patterns and contextual variables in understanding nativity differentials in child mortality.
\end{abstract}

\section{Introduction}

During the "classic" period of largely unrestricted immigration between the American Civil War and the introduction of stringent numerical quotas in the 1920s, the foreign-born population in the United States composed between 13 and 15 percent of the overall population, until recently the highest percentages in US history. The integration of these immigrants into American society has been a topic of social research for more than a century (e.g., Drachsler 1920; Gordon 1964; Walker 1891). Much of the focus has been on how immigrants fared in the labor market and how immigration affected the economic prospects of the native born and the US

(C) Social Science History Association, 2020. This is an Open Access article, distributed under the terms of the Creative Commons Attribution licence (http://creativecommons.org/licenses/by/4.0/), which permits unrestricted reuse, distribution, and reproduction in any medium, provided the original work is properly cited. 
economy at large (see Abramitzky and Boustan 2017). There has also been considerable interest in the marriage patterns of immigrants and intermarriage as an indicator of assimilation (Alba and Golden 1986; Lieberson and Waters 1988; Pagnini and Morgan 1990). "New" immigrant groups at the turn of the twentieth century from eastern and southern Europe were much less likely to intermarry with natives than "old" immigrant groups from northern and western Europe (Dribe et al. 2018; Sassler 2005; Wildsmith et al. 2003).

In the literature on the immigration of the late twentieth century there has also been a great interest in immigrants' health and mortality. Especially large attention has been devoted to the unexpectedly low mortality of immigrants of Hispanic origin, and the extent to which the mortality advantage among recent immigrants was associated with health-related behaviors or selection factors (e.g., Gutmann et al. 2000; Hummer et al. 1999, 2015; Singh and Hiatt 2006). For the historic immigration to the United States there has not been as much focus on these aspects of immigrant assimilation, although there are a few exceptions (e.g., Gutmann et al. 2000; Haines 2003; Preston and Haines 1991; Preston et al. 1994). With the recent release of more extensive historical data more detailed analyses are now possible. In this article, we estimate infant and child mortality among 14 immigrant groups and the native-born white population of native parentage (NWNP) at the turn of the twentieth century. We then model mortality as a function of a rich set of social, economic, and demographic variables. Our data come from new high-density samples of the 1900 and 1910 US censuses, which included several questions designed to measure immigrants' social and economic integration (e.g., occupation, literacy, ability to speak English, year of immigration, nativity, nativity of spouse, and nativity of parents). We supplement these data with new measures of area characteristics constructed from new complete-count census data collected by Ancestry.com (Ruggles et al. 2015). In relation to previous research our main contribution is to analyze the importance of contextual factors in explaining mortality differences among different immigrant groups. We do this by estimating county-level fixedeffects models and by studying the association of county-level variables measuring the size of immigrant populations, presence of natives, immigrant diversity, and overall child mortality for the native white population. In addition, we analyze how intermarriage, immigrant generation, and time spent in the United States shaped child mortality among immigrants in the United States.

\section{Theory and Previous Research}

Nativity differences in mortality stem from a variety of causes related to income, education, place of residence, housing quality, health-related behaviors, migrant selection, access to health care, and other factors. Some of these risk factors are relatively easy to measure while others are more difficult. Mosley and Chen (1984) models child survival using five sets of proximate determinants: maternal factors (e.g., mother's age, parity, and birth interval); injuries; nutrition; environmental contamination (e.g., disease environment and exposure); and illness control (e.g., preventive measures and medical treatment). Socioeconomic status, ethnicity, and immigrant's degree of assimilation into host society are all background factors 
that could have an impact on child survival through different connections to the proximate determinants (see Hummer et al. 1999). Socioeconomic status, for example, affects both nutrition and the potential environmental contamination through place of residence (see Van Poppel et al. 2005; Woods 2000).

Urban residence is a well-known risk factor for child health, especially in the early industrial era when hazardous emissions and diseases plagued cities (e.g., Condran and Crimmins 1980; Haines 2001). An important reason for high disease prevalence was deficient sanitation and impure water, which contributed to gastrointestinal (i.e., diarrheal) diseases, the leading killers of infants and young children (see, e.g., Burström et al. 2005; Cutler and Miller 2005; Ferrie and Troesken 2008; Jaadla and Puur 2016; Kesztenbaum and Rosenthal 2017; Troesken 2004; Van Poppel and van der Heijden 1997). Crowding, which facilitated the spread of infectious diseases such as measles, was also a contributing factor (Burström et al. 1999), although its effect can be difficult to isolate empirically (see Bernhardt 1995). Also within the urban context, higher incomes enabled families to avoid unhealthy areas and to afford housing of good quality. Socioeconomic status and education also affected parental child-rearing capabilities, by increasing parents' responsiveness to information about healthy behaviors and child-rearing practices (Caldwell 1979; Caldwell and McDonald 1982 ; Desai and Alva 1998). One such factor often stressed in the historical literature is breastfeeding. In the past, breastfeeding played the double role of delaying new pregnancies, thus giving more time for the mother to care for her current child and providing the infant with uncontaminated and healthy nutrition (e.g., Connor 2017; Olson and Thornton 2011; Preston and Haines 1991). In contexts where cow milk and water were often impure, such as in urban areas, breastfeeding could greatly reduce the risk of disease and mortality among young children. Because infant mortality forms a big part of total mortality under age five, breastfeeding can have a major impact on child mortality, in some contexts reinforcing the impact of low socioeconomic status, but in other contexts attenuating this association (see, e.g., Knodel and Kintner 1977; Olson and Thornton 2011; Preston et al. 1994; Woodbury 1925: 216-20; Woods et al. 1993).

Among immigrants, assimilation was likely of prime importance as well for child survival. "Classic" assimilation theory generally assumed that assimilation was a steady, "straight-line," multigenerational process in which immigrant groups acculturated by adopting native cultural patterns; progressively lost their ethnic culture, values, and behaviors; and eventually assimilated to the white Protestant, AngloSaxon "core culture" (e.g., Gordon 1964; Sandberg 1974). Although criticized by more recent scholars for its ethnocentrism and general assumption that the consequences of assimilation were all positive, classic assimilation theory continues to receive support from empirical studies of immigrants in the early twentieth century (see, e.g., Dribe et al. 2018; Gratton et al. 2007). More racially distinctive groups of immigrants after 1965 with a much wider variety of socioeconomic backgrounds than the earlier wave of immigrants, however, have experienced varying, nonlinear assimilation paths, with some groups assimilating toward upper- and middle-class norms and behaviors, some groups downwardly assimilating to lower-class norms, and other groups focusing on preservation of cultural values and behaviors while pursuing economic advancement, a type of "selective acculturation." This diversity of experiences has given rise to "segmented" assimilation theory with immigrant 
trajectories dependent on the social, economic, and racial contexts of the immigrant group, existing practices of ethnic and racial discrimination, and the temporal and spatial context of immigrants' entry to the United States (Alba and Nee 1997, 2003; Portes and Rumbaut 2001; Portes and Zhou 1993; Zhou 1997).

Given the early-twentieth-century context and the north and western European origins of most immigrant groups in this study, we expect that classic assimilation theory will be more pertinent to understanding group changes in infant and child mortality. Immigrants learning the native language - a first step of acculturation toward native-born norms - would be more likely to receive information about healthy child-rearing behavior than women without the ability to read or speak English. It is important to remember that the early twentieth century was a time of dramatic change in mortality throughout the Western world, partly related to improved nutrition following the industrial revolution (McKeown 1976), but to a large extent because of scientific discoveries and better knowledge about what caused different diseases and how they could be prevented (e.g., Easterlin 1999). Although public health projects aimed at cleaning water and milk supplies varied markedly among states and municipalities, information was spreading rapidly at the turn of the twentieth century; only five states lacked a board of public health in 1900 . Public health efforts in larger cities, where many recent immigrants lived, included public education campaigns aimed at reducing infant and child mortality (Condran, Williams, and Cheney 1984; Preston and Haines 1991: 20-26).

Thus, immigrants arriving from less developed countries than the United States were exposed to a flow of new information about how to properly take care of themselves and their children, and mastering English can be expected to have been important in accessing this information, as well as in getting access to basic health services, such as a family doctor. Exposure to the native population would be expected to have a similar effect. Immigrants residing in ethnic enclaves, such as New York City's 14th Ward in lower Manhattan, where Italians totally dominated the population in 1900 (Gabaccia 1984: 57), can be expected to have less exposure to information or resources than immigrants living in areas with larger percentages of natives. For similar reasons, we would expect second-generation immigrants to have a different mortality pattern than the first generation, and also that intermarriage and time spent in the United States would be associated with lower child mortality for most immigrant groups.

At the same time it is important to keep in mind that not all immigrants came from contexts with less knowledge and higher mortality than the United States. The low mortality of Jewish immigrants has, for example, often been noted, and has been related to their high rates of breastfeeding as well as their (religious) practice of washing hands before meals (e.g., Derosas 2003; Preston et al. 1994). An important factor behind lower mortality of some immigrants may also have been the better physical condition of the mothers as a result of better nutrition and less disease exposure in the home country, which would benefit the health and survival of their children (see, e.g., Bhalotra and Rawlings 2013). Convergence of mortality between low-mortality groups and the NWNP over time and across generations might imply classic assimilation to the NWNP_although in this particular case the consequences of the assimilation would be negative for the immigrant group — or reflect a shift to a more negative disease environment. Persistence or widening of a mortality 
advantage across time and generations among one or more groups concomitant with the group's acquisition of English-speaking ability and other aspects of assimilation, in contrast, suggests selective acculturation consistent with segmented assimilation theory (Portes and Zhou 1993; Zhou 1997).

If immigration pathways were highly segmented, we might also expect mortality trajectories of immigrant groups experiencing significant segregation and discrimination in the late nineteenth and early twentieth centuries, such as Italians and Mexicans (Gutmann et al. 2000; Lieberson 1980), to trend toward the mortality rates of the black population, which suffered sustained and significantly higher child mortality rates than the NWNP (Eriksson et al. 2018; Preston et al. 1994). In the literature on the health of contemporary immigrants in the United States there has been enormous research focus on the so-called Hispanic Paradox, that is, that immigrants from Latin America, and especially Mexico, have comparatively low mortality (Hummer et al. 2015), and that over time there seems to be a negative assimilation going on in the sense that their mortality increases with longer time spent in the United States and in the second generation (Landale et al. 2000). There has been intense debate over the causes behind this paradox. Although migrant selectivity, both in moving to the United States and in returning home, appears to be part of the explanation, it is not the whole explanation (Hummer et al. 2007; Markides and Eschbach 2005; Palloni and Arias 2004; Riosmena et al. 2013). Some research suggests that "othering" and discrimination are potential pathways leading to the erosion in the health of Mexican immigrants and their second-generation descendants, consistent with segmented assimilation theory (see, e.g., Viruell-Fuentes 2007).

In evaluating the role of assimilation in observed patterns of infant and child mortality, we focus on group patterns of convergence and divergence to the mortality trends of the native white population of native parentage. Previous research has indicated that much of the observed differences in group differentials can be explained by factors related to socioeconomic status and place of residence (see Preston et al. 1994), but there are also differences remaining after such controls. An interesting question is whether accounting for assimilation always leads to a convergence, as expected by classic "straight-line" immigration theory. If so, we can expect a positive association between mortality and assimilation for immigrants from low-mortality origins and a negative association for immigrants from high-mortality origins. Divergence and continued deviation from NWNP mortality patterns, however, especially among groups known to have experienced significant segregation and discrimination-and thus vulnerability to downward assimilation-would support theories of segmented assimilation.

\section{Data}

We rely on data from the 1900 and 1910 IPUMS census samples (Ruggles et al. 2015). Conducted during the high point of European immigration, the 1900 and 1910 censuses included information on birthplace and parental birthplaces, duration of marriage, ability to speak English, literacy, year of immigration, employment, occupation, the number of children ever born, and the number of children still surviving among ever-married women. As discussed in the following text, the latter two variables allow us to construct an index of infant and child mortality for each ever-married woman. 
The 1900 and 1910 IPUMS samples are higher-density samples than the ones used in previous studies of infant and child mortality. The new 6 percent 1900 IPUMS sample is 45 times larger than the original 1900 PUS (Preston and Higgs 1992) used in Preston and Haines's classic study Fatal Years (1991), while the new 1.4 percent 1910 IPUMS sample is nearly four times larger than the original 1910 PUS (Preston 1989) used by Preston et al. (1994). With these data we are able to take a closer look at differentials in infant and child mortality and control for unobserved spatial heterogeneity.

We also use the 1900 and 1910 complete-count microdata collected by Ancestry. com for the creation of county-level contextual variables. Although the potential for these data are enormous - the 1900 data set includes more than 76 million individual-level records while the 1910 data set includes more than 92 million-they have several limitations that prevented us from using them for the primary analysis. Both data sets, recently made available by the Minnesota Population Center, are in preliminary releases with large proportions of cases with missing information. The 1910 complete-count data set lacks key variables available in the 1910 IPUMS sample not collected by Ancestry.com, including times married, mother tongue, mother's mother tongue, and father's mother tongue (these variables were not collected by the 1900 census and are therefore not available in either the 1900 IPUMS sample or the 1900 complete-count data set). Both the 1900 and 1910 complete-count data sets lack consistently measured geographic information. Given these limitations, we decided to rely on the complete-count data only for the contextual information. The IPUMS samples provide a substantial number of cases for analysis across two census years while the complete-count data sets allow us to construct accurate estimates of contextual variables-relative group size, proportion of the population that was native-born white of native parentage, and so forth-even for small immigrant groups in small areas.

We analyze the mortality experience of children born in the United States to couples born in Canada, Britain (England, Scotland and Wales), Ireland, Germany, Denmark, Norway, Sweden, Netherlands, France, Italy, Russia, Mexico, Austria, and Hungary. ${ }^{1}$ These were the 14 largest nativity groups of European and North American origin living in the United States in 1910. We also included children born to second-generation couples with one or more parents from these countries. Given the known large race differentials in mortality among the native-born population of native parentage (Hacker and Haines 2005; Haines 2003; Preston and Haines 1991) and our selection of predominately white immigrant groups, we restricted our comparison group to the NWNP.

A few prior studies have imputed ethnicity in 1910 using birthplace, mother tongue, mother's mother tongue, and father's mother tongue (e.g., Preston et al. 1994). Unfortunately, the lack of mother tongue and parental mother tongue variables in the complete-count data sets do not allow the construction of ethnicity at the county level. Although we conducted our study of the 1910 census using both nativities and imputed ethnicities, we decided to limit our presentation to nativities because of our focus on contextual factors and because doing so also allows us to include analysis of the 1900 census. For many groups, nativity and imputed ethnicity

\footnotetext{
${ }^{1}$ Although Ireland had yet to obtain its independence, we treat it as an independent ancestry group, and not Scotland and Wales, because of the large number cases in the former.
} 
are nearly synonymous. A few nativity groups deserve special comment, however. Our Russian-born group contains about 50 percent Jews in 1910. For Austria and Hungary, the proportions Jews is 11 percent and 8 percent, respectively. Among the Canadians in our samples about 28 percent were French speakers and had a French mother tongue. This group has been identified as French-Canadian ethnicity by other researchers and has been shown to have one of the highest rates of infant and child mortality. English speakers born in Canada have been shown to have lower than average rates. There are also significant proportions of Canadian-born individuals with Irish, Slavic, and Italian origins. Our focus on nativity does not allow us to draw these distinctions, but in a separate analysis of the 1910 IPUMS sample we confirmed the higher child mortality among French-Canadians relative to Englishspeaking Canadians, as well as lower mortality of the Jewish population from Russia and Other European countries relative to non-Jews (detailed results not shown).

We included a number of variables at the individual level to measure assimilation, generation, and place of residence. We distinguished three different immigrant generations: $1 \mathrm{G}$ (foreign born arriving in the United States after the age of 12), 1.5G (foreign born arriving in the United States at age 12 or younger), and $2 \mathrm{G}$ (US born with at least one foreign-born parent). The second-generation ancestry was based on an individual's mother's nativity, unless she was born in the United States, in which case we based it on the individual's father's nativity.

We categorized marital outcomes into five different groups based on nativity and immigrant generation: $1 \mathrm{G}$ Endogamy (married to a spouse from the same ancestry), $2 \mathrm{G}$ endogamy (married to a second-generation spouse from the same nativity), NWNP Exogamy (married to a native-born white spouse with two native-born parents), 2G Exogamy (married to a second-generation spouse with at least one foreign-born parent from a different nativity), and Other Exogamy (married to any other spouse, including foreign-born and US-born nonwhites).

Place of residence distinguishes rural areas from urban areas of different sizes (2,500-9,999; 10,000-99,999; and 100,000 or more). In addition, we included an indicator for farm residence, as it can expected to be associated with better access to nutrition. Literacy and ability to speak English is included for both the wife and her husband. We also included an indicator of whether the mother was gainfully employed and her husband's occupational income score-a measure of the median earnings of the occupation in 1950 and an assumed proxy for socioeconomic status (Sobek 1995).

The complete count data identify birthplace, parental birthplaces, marital status, age, number of children ever born, number of children surviving, and state and county of residence. With these data we constructed four different contextual variables. We defined relative group size as the proportion of foreign born from the country group of birth in relation to the total population. The proportion NWNP is the share of the population in the county that was native-born white with two native-born parents. The degree of diversity of the immigrant population is measured by the diversity index $\left(D_{i}\right)$. It indicates the inverse probability that two randomly chosen foreign-born individuals in community $\mathrm{i}$ were from the same country of origin $\mathrm{j}$ :

$$
D_{i}=1-\sum_{j=1}^{k} p_{i j}^{2}
$$


where $\mathrm{p}_{\mathrm{ij}}$ is the proportion of origin group $\mathrm{j}$ in the immigrant population of community i. The diversity index ranges from 0 (no diversity) to 1 (complete diversity) (see Alesina et al. 2003; Simpson 1949). It was calculated based only on the foreign-born population to avoid high correlation with the proportion NWNP. Finally, we estimated the background mortality environment from the child mortality of NWNP. Specifically, we constructed a weighted mean index of infant and child mortality for currently married NWNP women aged 25-49 in each county using the "age model" described in UN Manual $X$ for indirect estimation methods (United Nations 1983: 76-81; see also Haines and Preston 1997), standardized to Model West life table level 13.5 (Coale and Demeny 1966) and discussed in more detail in the following text. ${ }^{2}$

Table 1 shows the descriptive statistics of the two census samples. In total we look at a combined study population of 500,977 women, corresponding to a total population of 16 million women with almost 60 million children ever born. About 61 percent of the women in the study population are NWNP. Among the ancestry groups (immigrants and their second-generation descendants), Germany, Ireland, and Britain were the three largest. A majority of the study population lived in rural areas (65 percent in 1900, and 61 percent in 1910); less than one-fifth lived in urban areas with a population of more than 100,000. Approximately 40 percent of the study population lived on a farm. More than 90 percent spoke English and were literate, while less than 5 percent of the women were employed. Looking only at the nonnative population (i.e., excluding the NWNP) about one-third were firstgeneration immigrants arriving as adults $(1 \mathrm{G}), 13$ percent were foreign born arriving as children $(1.5 \mathrm{G})$, and a little more than half belonged to the second generation (native born with at least one foreign-born parent). About 43 percent of the immigrants were married to a foreign-born spouse from the same ancestry and an additional 18-20 percent were married to a second-generation spouse from the same ancestry, indicating the great importance of endogamy among earlytwentieth-century immigrants (see Dribe et al. 2018). After limiting the study population to the foreign born ( $1 \mathrm{G}$ and $1.5 \mathrm{G}$ ), a majority of the women spent less than 10 years in the United States before getting married.

Table 2 displays descriptive statistics for the contextual variables at the county level. They are only measured for the sample of immigrants of the first and second generation. The mean of the mortality index was 0.92 in 1900 and 0.83 in 1910, showing the mortality decline taking place in this period. On average about 5 percent of the population in the county was from the same origin, and about 40 percent was NWNP. The average diversity index was about 0.75 in both census years. There was also a wide variation in the contextual variables across counties. The mortality index varied from 0.3 to 2.8 in 1900, and the relative group size from 0 to 0.5 . Similarly, the proportion NWNP varied from 0.03 to 0.99 , and the diversity index from 0 to 0.9 . Both variables varied in a similar manner in 1910. It is this

\footnotetext{
${ }^{2}$ Unfortunately, the complete-count data sets do not include the times married variable, which limited the accuracy of the marriage model. American data were used in the construction of Model West and previous studies have found that it closely approximates mortality in the early-twentieth-century United States (Preston and Haines 1991: ch. 2). As shown in the following text, level 13.5 was a very close fit for the mortality of children born to women in our samples.
} 
Table 1. Descriptive statistics of the sample (weighted means and proportions)

\begin{tabular}{|c|c|c|}
\hline & 1900 & 1910 \\
\hline \multicolumn{3}{|l|}{ Ancestry group (\%) } \\
\hline Native White Native Parentage & 61.5 & 61.2 \\
\hline Canada & 3.5 & 3.6 \\
\hline Britain & 4.9 & 4.4 \\
\hline Ireland & 9.1 & 6.9 \\
\hline Germany & 14.8 & 13.2 \\
\hline Denmark & 0.4 & 0.5 \\
\hline Norway & 1.3 & 1.3 \\
\hline Sweden & 1.4 & 1.4 \\
\hline Netherlands & 0.4 & 0.4 \\
\hline France & 0.5 & 0.4 \\
\hline Italy & 0.6 & 1.6 \\
\hline Russia & 0.6 & 1.9 \\
\hline Mexico & 0.3 & 0.4 \\
\hline Austria & 0.5 & 2.1 \\
\hline Hungary & 0.2 & 0.5 \\
\hline \multicolumn{3}{|l|}{ Place of residence $(\%)$} \\
\hline Rural & 64.6 & 60.6 \\
\hline Urban pop. $2,500-10,000$ & 7.2 & 7.9 \\
\hline Urban pop. $10,000-100,000$ & 11.5 & 12.9 \\
\hline Urban pop. $>100,000$ & 16.6 & 18.6 \\
\hline \multicolumn{3}{|l|}{ English speaker (\%) } \\
\hline No & 2.4 & 3.7 \\
\hline Yes/NA & 97.6 & 96.3 \\
\hline \multicolumn{3}{|l|}{ Spouse English speaker (\%) } \\
\hline No & 1.2 & 2.3 \\
\hline Yes/NA & 98.8 & 97.7 \\
\hline \multicolumn{3}{|l|}{ Literate (\%) } \\
\hline No/NA & 8.5 & 6.7 \\
\hline Yes (read and write) & 91.5 & 93.3 \\
\hline \multicolumn{3}{|l|}{ Spouse literate (\%) } \\
\hline No/NA & 7.3 & 6.4 \\
\hline Yes (read and write) & 92.7 & 93.6 \\
\hline
\end{tabular}


Table 1. (Continued)

\begin{tabular}{|c|c|c|}
\hline & 1900 & 1910 \\
\hline \multicolumn{3}{|l|}{ Woman employed (\%) } \\
\hline No & 98.0 & 95.1 \\
\hline Yes & 2.0 & 5.0 \\
\hline \multicolumn{3}{|l|}{ Farm residence $(\%)$} \\
\hline No & 57.3 & 61.7 \\
\hline Yes & 42.7 & 38.3 \\
\hline \multicolumn{3}{|l|}{ Children ever Born } \\
\hline 1 Child & 5.3 & 6.5 \\
\hline 2 Children & 10.4 & 12.3 \\
\hline 3 Children & 12.6 & 13.4 \\
\hline 4 Children & 13.1 & 13.0 \\
\hline 5 Children & 12.2 & 11.7 \\
\hline 6 Children & 11.1 & 10.6 \\
\hline 7 Children and + & 35.4 & 32.5 \\
\hline \multicolumn{3}{|l|}{ Immigrant generation $(\%)^{\star}$} \\
\hline $1 G$ & 32.8 & 33.9 \\
\hline $1.5 \mathrm{G}$ & 13.1 & 13.6 \\
\hline $2 G$ & 54.1 & 52.5 \\
\hline \multicolumn{3}{|l|}{ Intermarriage $(\%)^{\star}$} \\
\hline 1G Endogamy & 43.1 & 42.8 \\
\hline 2G Endogamy & 19.6 & 18.3 \\
\hline NWNP Exogamy & 17.4 & 18.0 \\
\hline 2G Exogamy & 11.1 & 12.6 \\
\hline Other Exogamy & 8.8 & 8.4 \\
\hline \multicolumn{3}{|l|}{ Time in US before marriage $(\%)^{\star \star}$} \\
\hline $0-4$ & 45.4 & 44.4 \\
\hline $5-9$ & 24.5 & 23.7 \\
\hline $10-14$ & 14.1 & 15.1 \\
\hline $15-19$ & 10.1 & 11.0 \\
\hline $20-24$ & 4.2 & 4.3 \\
\hline $25-29$ & 1.1 & 1.0 \\
\hline $30-34$ & 0.5 & 0.5 \\
\hline Age (mean) & 36.5 & 36.6 \\
\hline Mortality Reference Date (mean) & 8.5 & 8.9 \\
\hline Spouse occupation score (mean) & 21.6 & 22.5 \\
\hline
\end{tabular}


Table 1. (Continued)

\begin{tabular}{ccc}
\hline & 1900 & 1910 \\
\hline Sample N (women) & 365,385 & 135,592 \\
\hline Population (women) & $7,182,823$ & $9,132,756$ \\
\hdashline Population (children) & $27,297,022$ & $32,300,973$ \\
\hdashline${ }^{*} 1 G, 1.5 G$, and 2G: N & 139,924 & 53,241 \\
\hline${ }^{* *} 1$ IG and 2G: N & 60,672 & 23,653 \\
\hline
\end{tabular}

Source: IPUMS, Ruggles et al. 2015.

Table 2. Descriptive statistics for the contextual variables (sample: $1 \mathrm{G}, 1.5 \mathrm{G}, 2 \mathrm{G}$ )

\begin{tabular}{|c|c|c|c|c|}
\hline 1900 & Mean & Std. Dev. & Min & Max \\
\hline Mortality index (NWNP) & 0.923 & 0.169 & 0.275 & 2.786 \\
\hline Relative group size & 0.059 & 0.050 & 0.000 & 0.499 \\
\hline Proportion NWNP & 0.411 & 0.192 & 0.029 & 0.992 \\
\hline Diversity index & 0.735 & 0.133 & 0.000 & 0.900 \\
\hline 1910 & Mean & Std. Dev. & Min & Max \\
\hline Mortality index (NWNP) & 0.832 & 0.161 & 0.405 & 2.159 \\
\hline Relative group size & 0.055 & 0.060 & 0.000 & 0.479 \\
\hline Proportion NWNP & 0.404 & 0.186 & 0.012 & 0.987 \\
\hline Diversity index & 0.759 & 0.166 & 0.004 & 0.900 \\
\hline
\end{tabular}

Source: See table 1.

variation at the county level that we used to study the associations between the contextual factors and child mortality.

As shown in figures 1 and 2, the background mortality environment, as proxied by infant and child mortality among children born to NWNP women, varied substantially by county. Some of this heterogeneity, of course, reflected higher infant and child mortality in higher population density areas, lower mortality in rural areas, and differences in public health improvement efforts. But there were many areas of unexpected high child mortality in rural areas, such as in the Arkansas, Missouri, Illinois, Kentucky, and Mississippi counties bordering the Mississippi and Arkansas Rivers, the Anthracite coal mining counties in eastern Pennsylvania, northern counties in Minnesota, Wisconsin and Michigan, lowland counties of the Carolinas and Florida, and sparsely populated counties in Arizona and New Mexico Territories. The geographic patterns were largely consistent in both census years. The maps strongly suggest that the inclusion of urban-rural and regional dummy variables - the approach used in most prior research — would be insufficient in controlling for geographic differentials in the mortality environment. In the subsequent analysis we apply county-level fixed effects to account for this diversity in experience and, in some models, included the mean mortality value for each county as a control for the baseline mortality environment. 


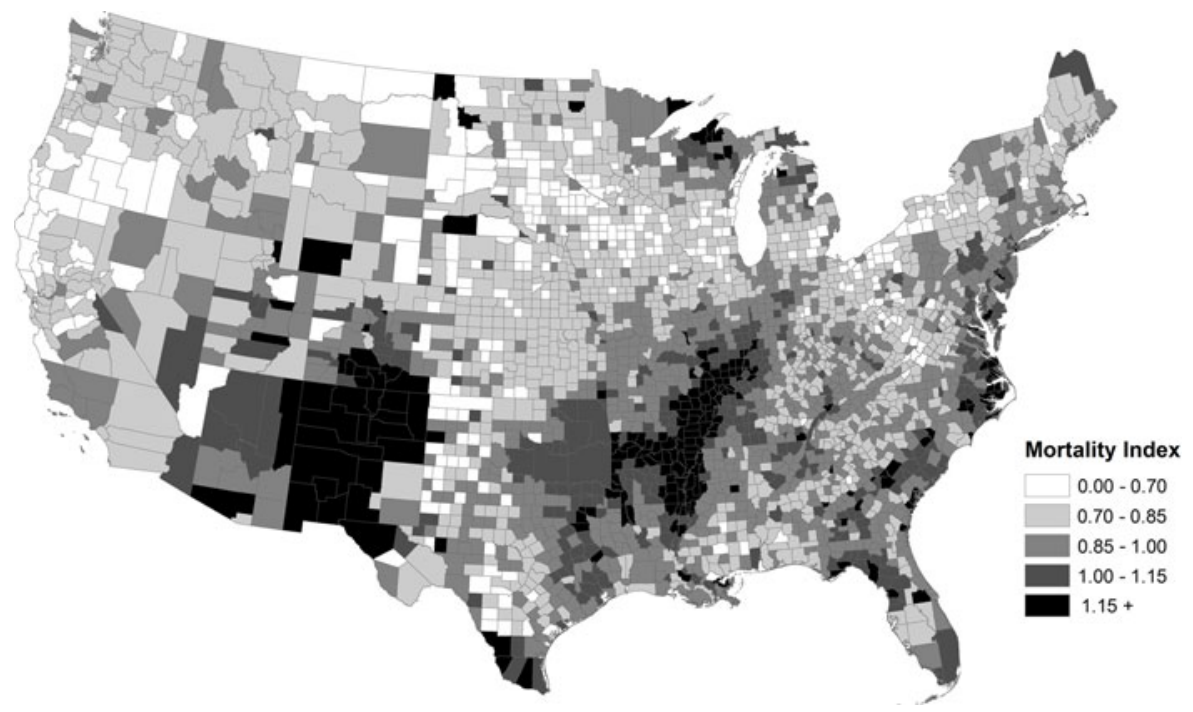

Figure 1. Child mortality index by county, United States, 1900 Census.

Source: See Table 1.

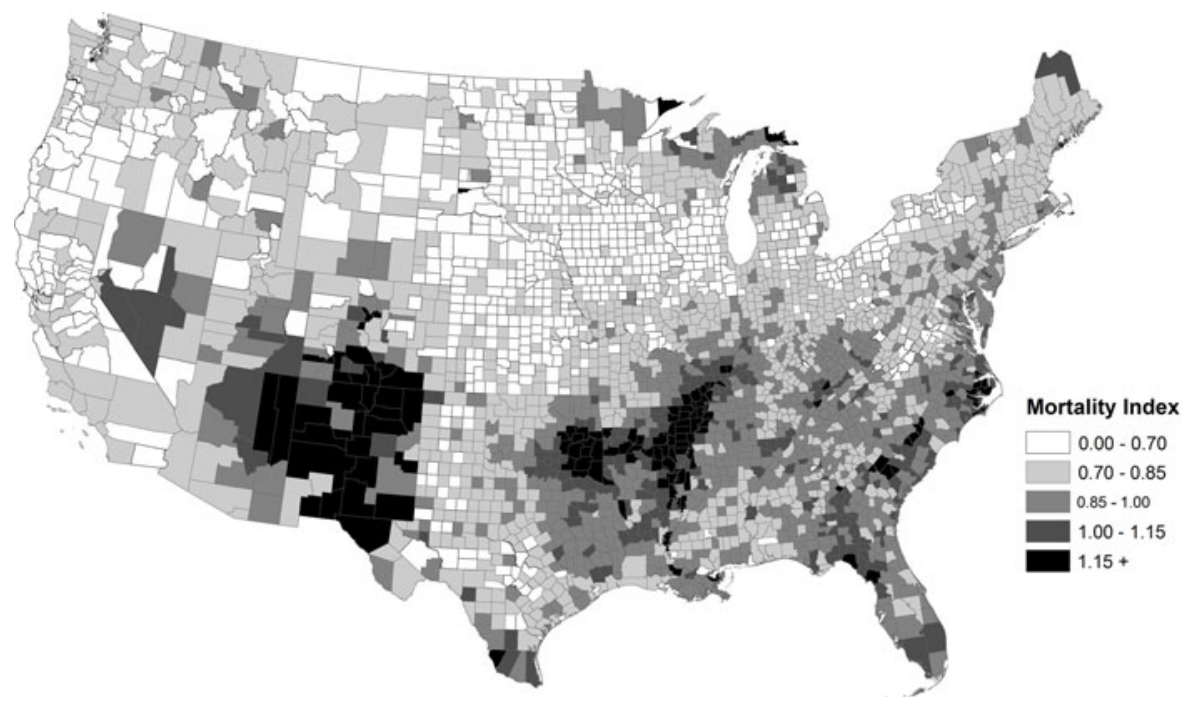

Figure 2. Child mortality index by county, United States, 1910 Census.

Source: See Table 1.

\section{Methods}

We constructed indirect estimates of infant and child mortality from census questions on the number of live births that an ever-married woman had in her life (i.e., parity or children ever born) and how many of those children were still living (i.e., children surviving). The two questions were asked to all ever-married women 
in the 1900 and 1910 censuses. Because of our focus on child mortality, all women in our sample were mothers of one or more children. The method has been detailed elsewhere (Haines and Preston 1997; Preston and Haines 1991; United Nations 1983). Briefly, a mortality index was constructed for each mother by dividing the number of actual child deaths she experienced by the expected number of deaths. The latter was based on her parity, children's length of exposure to the risk of dying (proxied by the mother's duration of marriage or age), the overall age pattern of fertility of women in her cohort, and the model life table chosen as a standard. We relied on the "age model," which could be constructed for both the 1900 and 1910 IPUMS samples and the complete-count data sets. We limited our universe to currently married white mothers aged 20-49 years with spouses present in the household. ${ }^{3}$

The mortality index is readily interpretable. Values above 1.0 mean that children born to the woman (or a group of women) experienced child mortality rates above the rates expected by the standard life table, while values below 1.0 means that the children experienced mortality rates below the standard. We relied on Model West level 13.5 for our standard (Coale and Demeny 1966), which indicates an infant mortality probability $\left({ }_{1} q_{0}\right)$ of 0.122 (both sexes combined) and expectation of life of about 51 years. Any mortality parameter desired can be obtained by multiplying the index by the appropriate value in the standard table. A mortality index of 0.90 for a population subgroup, for example, can be combined with the ${ }_{5} q_{0}$ value in the standard table-in our case 0.1793 - to yield an estimated ${ }_{5} q_{0}$ value of 0.1614 , indicating that approximately 16.1 percent of children in the subgroup died before reaching age 5 (Hacker and Haines 2005).

In the multivariate analysis we use linear regression (OLS) with the mortality index at the individual level as the dependent variable. Prior research has shown the mortality index to be robust and econometrically well-behaved when used as a dependent variable in regression models (Trussell and Preston 1982). Because infant and child mortality was declining in the early-twentieth-century United States, however, the index will be biased by differences in the timing of children's deaths among women of different ages and parity. To account for this bias, we constructed a variable called the mortality reference date (MRD), which is the midpoint of the period to which the mortality estimates refer to for each woman (see detailed description in United Nations 1983; see also Haines and Preston 1997). MRD is expressed in years before the census of 1900 or 1910. The regressions are weighted

\footnotetext{
${ }^{3}$ The 1910 census was the first census to ask marriage number. Unfortunately, the times married variable was not collected by Ancestry.com and is not available in the complete count data set. In the age model, children's mortality corresponds approximately to age 1 for mother's age 15-19, age 2 for mother's age 20-25, age 3 for mother's 25-29, age 5 for mother's age 30-34, age 10 for mother's age 35-39, and so forth. Extensive study of the reliability of the age model by Preston and Haines (see Preston and Haines 1991: 73-74) with a much smaller sample indicated mortality estimates are less reliable for children born to mothers under age 25 because of fewer births, fewer deaths, and likely recentness of most mothers' marriages, which exacerbates estimation of children's exposure to risk. We found erratic results among children born to women under age 20 but generally consistent-although moderately higher mortality (about 7 percent higher than among the children born to mothers age 25-29)-among children born to mothers age 20-24. Although Preston and Haines's suggested disregarding age-model estimates of $\mathrm{q}(1)$ from mothers age 15-19 and $q(2)$ from mothers age 20-24, we decided to retain the latter, reasoning that the higher mortality among children of mothers in this age group may be explained by higher-than-average mortality in parity one births and among children of younger mothers.
} 
by the number of children born and the sampling weights to reflect the population of children at risk of mortality, even though the unit of analysis is currently married women.

We start by estimating a basic model with controls for age and nativity. This gives an estimate of gross differentials in child mortality. We then add variables measuring place of residence and assimilation, which gives an idea about how much of the raw nativity differences can be explained by these factors. In this model we also include the MRD and children ever born. Subsequently we add county-level fixed effects to account for unobserved variables at the county level. Finally, we study the association between four county-level contextual factors and child mortality: relative group size, proportion NWNP, the mean mortality index for NWNP, and the diversity index for the foreign-born population. ${ }^{4}$

\section{Empirical Findings}

\section{Nativity Differences}

We start by looking at the mortality index by nativity in table 3 . The mean for the study population in 1900 is 0.96 , which is equivalent to a ${ }_{5} q_{0}$ value of 0.172 . The estimate is very close to the 0.167 index estimated by Preston and Haines (1991: 68) for the white population in the original 1900 PUS. For 1910, the mean is 0.87 , which is equivalent to a ${ }_{5} q_{0}$ value of 0.156 , close to Preston et al.'s estimate of 0.164 estimated with the original 1910 PUS (1994: 43).

Our results largely confirm prior findings (Gutmann et al. 2000; Haines and Preston 1997; Preston and Haines 1991; Preston et al. 1994) while providing some additional details. NWNP children had somewhat lower child mortality than the overall mean. Children of Mexican ancestry suffered the highest levels of infant and child mortality (68 percent higher than NWNP in 1900 and 73 percent higher in 1910), followed by children born to Italian, Irish, Hungarian, Canadian, French, and Austrian mothers. Child mortality among children of Mexican ancestry was approximately equal to that experienced by the African American population (Preston and Haines 1991; Preston et al. 1994). Clearly, there was no "Hispanic Paradox" in early-twentieth-century child mortality. It is perhaps no coincidence that Mexican and Italian immigrants were more recent arrivals to the United States compared to most other groups in the study population and suffered from discrimination in the labor market and residential segregation. Mexican immigration was relatively low until the Mexican Revolution in 1910, after which the Hispanic population in the United States rose above 1 percent for the first time (Gratton and Gutmann 2000). Notwithstanding their low numbers, Mexican immigrants in the late nineteenth and early twentieth centuries faced particularly virulent discrimination, segregated schools, mob violence, and even lynching (Carrigan and Web 2013; De León 1982). However, Jews also experienced

\footnotetext{
${ }^{4}$ Several of the control variables in the models-age, children ever born, and MRD-are collinear. Because we were uninterested in the size or statistical significance of these variables, we were willing accept multicollinearity among them in an attempt to control as much of the demographic and temporal variation in mortality as possible.
} 
Table 3. Mortality index by ancestry group (weighted means)

\begin{tabular}{|c|c|c|c|c|c|}
\hline & \multicolumn{2}{|c|}{1900} & \multicolumn{2}{|c|}{1910} & \multirow[t]{2}{*}{ \%change } \\
\hline & Mean & s.e. & Mean & s.e. & \\
\hline NWNP & 0.93 & 0.00 & 0.86 & 0.00 & -7.6 \\
\hline Canada & 1.07 & 0.01 & 0.99 & 0.02 & -7.6 \\
\hline Britain & 1.01 & 0.01 & 0.91 & 0.02 & -10.0 \\
\hline Ireland & 1.17 & 0.01 & 1.01 & 0.02 & -13.8 \\
\hline Germany & 0.94 & 0.01 & 0.81 & 0.01 & -14.2 \\
\hline Denmark & 0.80 & 0.03 & 0.69 & 0.04 & -14.0 \\
\hline Norway & 0.78 & 0.02 & 0.70 & 0.03 & -9.3 \\
\hline Sweden & 0.80 & 0.02 & 0.69 & 0.03 & -14.2 \\
\hline Netherlands & 0.86 & 0.04 & 0.68 & 0.05 & -20.9 \\
\hline France & 1.03 & 0.03 & 0.89 & 0.06 & -13.8 \\
\hline Italy & 1.30 & 0.04 & 1.10 & 0.03 & -15.6 \\
\hline Russia & 0.81 & 0.03 & 0.84 & 0.03 & 3.3 \\
\hline Mexico & 1.56 & 0.06 & 1.49 & 0.07 & -4.4 \\
\hline Austria & 1.02 & 0.03 & 0.92 & 0.03 & -10.0 \\
\hline Hungary & 1.14 & 0.06 & 0.98 & 0.05 & -14.1 \\
\hline Total & 0.96 & 0.00 & 0.87 & 0.00 & -9.4 \\
\hline $\mathrm{N}$ & & & & & \\
\hline
\end{tabular}

Note: Mortality index calculated based on the Model West 13.5 life table (Coale and Demeny 1966). Source: See table 1.

significant discrimination and residential segregation but enjoyed lower child mortality than other groups (Preston et al. 1994; White et al. 1994).

Other ancestry groups had lower than average mortality levels, with children of Scandinavian and Russian ancestry having the lowest mortality. With the larger number of cases in the new 1900 and 1910 IPUMS samples, we were able to provide separate estimates for children born to mothers from Denmark, Norway, and Sweden-rather than aggregating them in the category "Scandinavian" as other researchers were forced to do-but the results are very similar to each other. The low mortality among children of Russian ancestry can be explained by the dominance of Jews among the Russian immigrants; a group known for its hygienic practices, strict rules about food, extensive breastfeeding, and low infant mortality (Derosas 2003; Preston et al. 1994: 66-69). The ranking of countries remains similar in 1910, although child mortality declined by about 8 percent overall. The Dutch, Irish, Germans, Swedes, Italians, and Hungarians experienced infant and child mortality declines of more than 10 percent between 1900 and 1910, Mexicans a decline of only 5 percent, while Russians experienced a modest increase. It is, of course, premature to put too much interpretation into these differences before analyzing more in depth how they depended on residential patterns or the degree of assimilation into US society. 
Table 4. Under 5 mortality $\left({ }_{5} q_{0}\right)$ comparisons. US ancestry groups and country of origin

\begin{tabular}{|c|c|c|c|c|}
\hline & US & Origin & US & Origin \\
\hline & 1900 & 1890 & 1910 & 1900 \\
\hline Britain & 0.18 & 0.23 & 0.16 & 0.23 \\
\hline Denmark & 0.14 & 0.21 & 0.12 & 0.16 \\
\hline Norway & 0.14 & 0.18 & 0.13 & 0.13 \\
\hline Sweden & 0.14 & 0.18 & 0.12 & 0.16 \\
\hline Netherlands & 0.15 & 0.26 & 0.12 & 0.22 \\
\hline France & 0.19 & 0.25 & 0.16 & 0.23 \\
\hline Italy & 0.23 & 0.33 & 0.20 & 0.30 \\
\hline
\end{tabular}

Note: Country of origin Britain is England and Wales. ${ }_{5} q_{0}$ for US ethnic groups are calculated by multiplying the mortality index in table 2 with ${ }_{5} q_{0}$ from Model West 13.5 life table (0.17927). As the US data are based on indirect estimation they reflect mortality centered about 10 years prior to the census. The country-of-origin data are from period life tables and therefore the comparison year is 10 years earlier than the indirect estimate, i.e., 1900 US is compared with 1890 at origin, and 1910 US is compared with 1900 at origin.

Source: See table 1. ${ }_{5} q_{0}$ for countries of origin from the Human Mortality Database (www. humanmortality.org).

In table 4 we compare the implied ${ }_{5} q_{0}$ s for origin groups in 1900 and 1910 with ${ }_{5} q_{0}$ s circa 1890 and 1900 in countries with available life table data in the Human Mortality Database (www.humanmortality.org). The reason for comparing our estimates with data 10 years prior is that they reflect mortality centered about 10 years before the census (see the MRDs in table 1). For all countries for which we have data, mortality levels were lower among immigrant groups in the United States than in their respective countries of origin, supporting the idea that migration to the United States may have improved immigrants' socioeconomic status and health. It is also likely that immigrants were positively selected for health. If so, this finding supports research emphasizing that immigrants are quite healthy relative to nonmigrants in the sending countries, although the strength of the selection mechanism has been found to vary across countries (Jasso et al. 2004; Marmot et al. 1984). As could be expected, mortality differences were larger between the countries of origin than between US immigrant groups, but overall the ranking of countries was similar. Moreover, the pattern did not change much over time.

Turning to the multivariate analysis, table 5 shows regression estimates for three models: a basic model controlling only for age and age squared (M1); a full model with all individual-level variables and additional controls for MRD and children ever born (M2); and the full model with county-level fixed effects (M3). By comparing the estimates in the basic and full model we can get a rough idea of how much the variables related to assimilation and place of residence contributed to explaining the observed nativity differences in child mortality. We find significant differentials between the NWNP and most groups, even after the addition of controls for assimilation, residence, and socioeconomic status. Interestingly, however, large differentials in infant and child mortality between Italians and the NWNP in 1900 were not statistically significant in model M2, suggesting that much of observed differences in 
Table 5. Regression estimates, mortality index (weighted OLS)

\begin{tabular}{|c|c|c|c|c|c|c|}
\hline \multicolumn{7}{|l|}{ A. 1900} \\
\hline & \multicolumn{2}{|c|}{ M1 } & \multicolumn{2}{|c|}{ M2 } & \multicolumn{2}{|c|}{ M3 (FE) } \\
\hline & Coef & $P>t$ & Coef & $P>t$ & Coef & $P>t$ \\
\hline \multicolumn{7}{|l|}{ Ancestry } \\
\hline NWNP & ref & ref & ref & ref & ref & ref \\
\hline Canada & 0.146 & 0.000 & 0.044 & 0.001 & 0.063 & 0.000 \\
\hline Britain & 0.073 & 0.000 & 0.014 & 0.189 & 0.028 & 0.010 \\
\hline Ireland & 0.241 & 0.000 & 0.048 & 0.000 & 0.035 & 0.000 \\
\hline Germany & 0.012 & 0.067 & -0.107 & 0.000 & -0.080 & 0.000 \\
\hline Denmark & -0.120 & 0.000 & -0.143 & 0.000 & -0.068 & 0.039 \\
\hline Norway & -0.154 & 0.000 & -0.169 & 0.000 & -0.072 & 0.000 \\
\hline Sweden & -0.122 & 0.000 & -0.147 & 0.000 & -0.086 & 0.000 \\
\hline Netherlands & -0.075 & 0.035 & -0.174 & 0.000 & -0.134 & 0.000 \\
\hline France & 0.098 & 0.004 & -0.002 & 0.939 & 0.016 & 0.629 \\
\hline Italy & 0.384 & 0.000 & -0.067 & 0.069 & -0.072 & 0.054 \\
\hline Russia & -0.104 & 0.000 & -0.437 & 0.000 & -0.478 & 0.000 \\
\hline Mexico & 0.636 & 0.000 & 0.138 & 0.012 & 0.158 & 0.014 \\
\hline Austria & 0.104 & 0.003 & -0.181 & 0.000 & -0.168 & 0.000 \\
\hline Hungary & 0.231 & 0.000 & -0.151 & 0.007 & -0.142 & 0.013 \\
\hline \multicolumn{7}{|l|}{ Place of residence } \\
\hline Rural & & & ref & ref & ref & ref \\
\hline Urban pop. $2,500-10,000$ & & & 0.048 & 0.000 & 0.053 & 0.000 \\
\hline Urban pop. $10,000-100,000$ & & & 0.121 & 0.000 & 0.090 & 0.000 \\
\hline Urban pop. $>100,000$ & & & 0.256 & 0.000 & 0.157 & 0.000 \\
\hline \multicolumn{7}{|l|}{ English speaker } \\
\hline No & & & 0.156 & 0.000 & 0.097 & 0.000 \\
\hline Yes & & & ref & ref & ref & ref \\
\hline \multicolumn{7}{|l|}{ Spouse English speaker } \\
\hline No & & & 0.217 & 0.000 & 0.099 & 0.001 \\
\hline Yes & & & ref & ref & ref & ref \\
\hline \multicolumn{7}{|l|}{ Literate } \\
\hline No & & & ref & ref & ref & ref \\
\hline Yes & & & -0.102 & 0.000 & -0.092 & 0.000 \\
\hline \multicolumn{7}{|l|}{ Spouse literate } \\
\hline No & & & ref & ref & ref & ref \\
\hline Yes & & & -0.053 & 0.000 & -0.064 & 0.000 \\
\hline
\end{tabular}


Table 5. (Continued)

\begin{tabular}{|c|c|c|c|c|c|c|}
\hline \multicolumn{7}{|l|}{ A. 1900} \\
\hline & \multicolumn{2}{|c|}{ M1 } & \multicolumn{2}{|c|}{ M2 } & \multicolumn{2}{|c|}{ M3 (FE) } \\
\hline Spouse occupational income score & & & -0.0001 & 0.554 & -0.0003 & 0.312 \\
\hline \multicolumn{7}{|l|}{ Woman employed } \\
\hline No & & & ref & ref & ref & ref \\
\hline Yes & & & 0.186 & 0.000 & 0.191 & 0.000 \\
\hline \multicolumn{7}{|l|}{ Farm residence } \\
\hline No & & & ref & ref & ref & ref \\
\hline Yes & & & -0.226 & 0.000 & -0.204 & 0.000 \\
\hline Constant & 1.224 & 0.000 & 2.477 & 0.000 & 2.454 & 0.000 \\
\hline Number of obs & 365,385 & & 365,385 & & 365,385 & \\
\hline $\mathrm{F}$ & 99.7 & & 595.7 & & 506.6 & \\
\hline Prob $>F$ & 0.000 & & 0.000 & & 0.000 & \\
\hline R-squared & 0.007 & & 0.065 & & 0.086 & \\
\hline \multicolumn{7}{|l|}{ B. 1910} \\
\hline & \multicolumn{2}{|c|}{ M1 } & \multicolumn{2}{|c|}{ M2 } & \multicolumn{2}{|c|}{ M3 (FE) } \\
\hline & Coef & $P>t$ & Coef & $P>t$ & Coef & $P>t$ \\
\hline \multicolumn{7}{|l|}{ Ancestry } \\
\hline NWNP & ref & ref & ref & ref & ref & ref \\
\hline Canada & 0.127 & 0.000 & 0.043 & 0.036 & 0.063 & 0.004 \\
\hline Britain & 0.035 & 0.059 & 0.017 & 0.357 & 0.039 & 0.039 \\
\hline Ireland & 0.137 & 0.000 & 0.030 & 0.060 & 0.028 & 0.095 \\
\hline Germany & -0.063 & 0.000 & -0.118 & 0.000 & -0.079 & 0.000 \\
\hline Denmark & -0.177 & 0.000 & -0.168 & 0.000 & -0.073 & 0.111 \\
\hline Norway & -0.163 & 0.000 & -0.155 & 0.000 & -0.052 & 0.120 \\
\hline Sweden & -0.181 & 0.000 & -0.172 & 0.000 & -0.101 & 0.001 \\
\hline Netherlands & -0.194 & 0.000 & -0.242 & 0.000 & -0.097 & 0.072 \\
\hline France & 0.024 & 0.684 & -0.017 & 0.761 & 0.006 & 0.914 \\
\hline Italy & 0.256 & 0.000 & -0.136 & 0.000 & -0.136 & 0.000 \\
\hline Russia & -0.010 & 0.718 & -0.272 & 0.000 & -0.289 & 0.000 \\
\hline Mexico & 0.640 & 0.000 & 0.224 & 0.001 & 0.246 & 0.002 \\
\hline Austria & 0.068 & 0.018 & -0.172 & 0.000 & -0.142 & 0.000 \\
\hline Hungary & 0.139 & 0.009 & -0.123 & 0.019 & -0.128 & 0.017 \\
\hline
\end{tabular}


Table 5. (Continued)

\begin{tabular}{|c|c|c|c|c|c|c|}
\hline \multicolumn{7}{|l|}{ B. 1910} \\
\hline & \multicolumn{2}{|c|}{ M1 } & \multicolumn{2}{|c|}{ M2 } & \multicolumn{2}{|c|}{ M3 (FE) } \\
\hline Rural & & & ref & ref & ref & ref \\
\hline Urban pop. $2,500-10,000$ & & & -0.001 & 0.960 & 0.000 & 0.975 \\
\hline Urban pop. $10,000-100,000$ & & & 0.069 & 0.000 & 0.065 & 0.000 \\
\hline Urban pop. $>100,000$ & & & 0.170 & 0.000 & 0.099 & 0.000 \\
\hline \multicolumn{7}{|l|}{ English speaker } \\
\hline No & & & 0.150 & 0.000 & 0.120 & 0.000 \\
\hline Yes & & & ref & ref & ref & ref \\
\hline \multicolumn{7}{|l|}{ Spouse English speaker } \\
\hline No & & & 0.089 & 0.013 & 0.051 & 0.153 \\
\hline Yes & & & ref & ref & ref & ref \\
\hline \multicolumn{7}{|l|}{ Literate } \\
\hline No & & & ref & ref & ref & ref \\
\hline Yes & & & -0.132 & 0.000 & -0.105 & 0.000 \\
\hline \multicolumn{7}{|l|}{ Spouse literate } \\
\hline No & & & ref & ref & ref & ref \\
\hline Yes & & & -0.094 & 0.000 & -0.090 & 0.000 \\
\hline Spouse occupational income score & & & -0.002 & 0.000 & -0.003 & 0.000 \\
\hline \multicolumn{7}{|l|}{ Woman employed } \\
\hline No & & & ref & ref & ref & ref \\
\hline Yes & & & 0.183 & 0.000 & 0.187 & 0.000 \\
\hline \multicolumn{7}{|l|}{ Farm residence } \\
\hline No & & & ref & ref & ref & ref \\
\hline Yes & & & -0.224 & 0.000 & -0.211 & 0.000 \\
\hline Constant & 0.936 & 0.000 & 2.058 & 0.000 & 2.005 & 0.000 \\
\hline Number of obs & 135,592 & & 135,592 & & 135,592 & \\
\hline $\mathrm{F}$ & 36.0 & & 170.2 & & 145.2 & \\
\hline Prob $>F$ & 0.000 & & 0.000 & & 0.000 & \\
\hline R-squared & 0.006 & & 0.053 & & 0.089 & \\
\hline
\end{tabular}

Source: See table 1.

Note: Control variables include age, age-squared (M1, M2, and M3), mortality reference date, and number of children ever born (M2 and M3). 
the basic model are explained by Italians' disproportionate residence in unhealthy urban areas, relatively low socioeconomic standing, and relatively low level of societal integration (language and literacy).

Given the large spatial differentials in mortality observed at the county level (see figures 1 and 2), we expected that the introduction of urban and regional dummy variables (Preston and Haines 1991; Preston et al. 1994) would be inadequate in controlling for unobserved heterogeneity. Comparing the full model and the fixed-effects model (M3) shows the contribution of unobserved county-level factors in explaining the ancestry differentials.

We begin by comparing the estimates for nativity across the different models. The results are similar in both census years. In most cases, mortality differences relative to the white population of native parentage are smaller in the full- and fixed-effects models, implying that some of the gross differences can be explained by place of residence and the assimilation variables included in the models. This is evident for Canadians, Irish, Italians, Mexicans, Austrians, and Hungarians. For Scandinavian and Dutch immigrants there were also considerable differences between the full and fixed-effects models (Models 2 and 3), indicating that unobserved factors at the county level are important explanations for mortality differentials. For the other nativities, unobserved county-level factors do not seem to explain much of the mortality differences in addition to what was explained by the individual-level factors capturing place of residence and aspects of assimilation, including ability to speak English, literacy, and socioeconomic status (occupational income score). If we limit the analysis only to the immigrant population it is also clear that generation and intermarriage did not explain much of the remaining nativity differences (detailed results not shown).

Most notably for Russian immigrants, the mortality advantage relative to nativeborn whites of native parentage was considerably greater after controlling for assimilation and place of residence. Without controls, the Russian population enjoyed a 10 percent advantage in child mortality. In the fixed-effects model with controls for residence and ability to speak English, Russian child mortality in 1900 was 48 percent lower than that of native whites of native parentage. This difference is largely explained by residential patterns; specifically that the Russians were more likely to live in unhealthy urban areas, which partly counterweighed their good health behaviors.

Although the observed individual- and family-level variables capturing immigrant integration and place of residence, as well as the community-level variables, explained a considerable part of overall nativity differences, some residual differences remained in the fully controlled models. For some country groups the residual differences were substantial. All else being equal, immigrants from Canada and Ireland had modestly higher child mortality than native whites of native parentage, while immigrants from Mexico had much higher mortality. Immigrants from the Netherlands, Hungary, Austria, and especially Russia experienced child mortality more than 10 percent lower than NWNP, net of all controls. There are a few unobserved factors that may explain these differences. For Russians, and to a lesser extent for Hungarians and Austrians, lower mortality was likely related to the specific characteristics of the Jewish population, who represented about half and the Russian population in the United States and significant proportions of the Hungarian and Austrian populations. 
Other factors, including positive immigrant selection and health-related behaviors probably played significant roles. Breastfeeding was most likely responsible for the high residual child mortality among Canadian immigrants, among whom French-speakers were found to have had exceptionally short breastfeeding in a study of eight US cities conducted by the Children's Bureau between 1911 and 1915 (Preston et al. 1994; Woodbury 1925). In a study of nineteenth-century Montreal, Olson and Thornton also reported much higher infant mortality among French speakers than other groups, which they associated with early weaning, deficient sanitary systems, and impure water (Olson and Thornton 2011: 95-103). ${ }^{5}$

High child mortality for Mexican immigrants in the United States has previously been connected to bad sanitation and water system in areas with high concentrations of Hispanic immigrants (Gutmann et al. 2000). Unfortunately, the Children's Bureau study of breastfeeding practices did not include Hispanic or Mexican-born women. Although we can only speculate about factors not included in our analysis, the much higher mortality among Mexicans in the United States suggests multiple causes, perhaps related to maternal health, child care practices, discrimination within occupational categories, breastfeeding practices, and within-county differences in housing, water quality, and sanitation. In any case, there is no evidence for a Hispanic paradox in child mortality in 1900 similar to the one for adults in the contemporary United States.

As expected, residence in a larger urban area was related to higher infant and child mortality. The "urban penalty" appears to have been the normal pattern in preindustrial and early-industrial societies (Condran and Crimmins-Gardner 1978; Haines 2001; Preston and Haines 1991; Woods 2000), likely because of poor sanitary conditions and housing. Non-English speakers experienced substantially higher mortality than English speakers, but there was no added impact of having a non-English-speaking spouse. As expected, literacy was associated with lower child mortality, and there was an additional association with one's spouse being literate. Children born to mothers employed in the paid labor force experienced higher mortality than children of nonemployed mothers, which could be related to neglect of children, lack of breastfeeding, and selection effects related to poverty: families dependent on women's work for subsistence in 1900 were also likely to have lower capabilities in caring for children and other unobserved factors related to infant and child mortality. Finally, living on a farm was associated with lower child mortality over and above simply living in rural areas. This could be related to better access to food and higher-quality housing on farms than in rural areas. We should be wary about assuming that all farms were good places to raise healthy children, however; medical knowledge and care on most farms was probably poor relative to urban areas. In addition, figures 1 and 2 demonstrate that many rural areas suffered high rates of infant and child mortality.

\footnotetext{
${ }^{5}$ As mentioned in the preceding text, the 1900 IPUMS sample and the 1900 and 1910 IPUMS completecount data sets lacks the necessary variables (language spoken, mother tongue, mother's mother tongue, and father's mother tongue) to infer within-country ethnicities. This shortcoming is particularly vexing for Russia and some central and eastern European countries (Jewish, non-Jewish) and Canada (Englishspeaking, French-speaking, Irish ancestry, and others), but is also problematic for all countries with diverse populations, including Great Britain.
} 
The patterns in 1910 were similar to the ones in 1900 (table 5, panel B). Overall, nativity differences were similar, and as in 1900 they were to a considerable extent explained by individual-, family-, and community-level factors. However, some differences remained and in some cases differences were more pronounced in the models with control variables. Similar to 1900, immigrants originating in Canada and Mexico had consistently higher mortality than the NWNP in all model specifications, while only the Russians and Swedish had consistently lower child mortality than the NWNP. Despite the continued advantage in child mortality among Russians (29 percent lower than NWNP in the fully controlled fixed-effects model), the advantage was considerably less than the advantage in 1900 (48 percent lower than the NWNP), consistent with the increase in mortality between 1900 and 1910 noted in table 3. In addition to the Swedish, immigrants from Italy, Austria, and Hungary enjoyed childhood mortality rates more than 10 percent lower than the NWNP population.

As was true in 1900, we expect that a few unobserved factors, particularly mothers' ethnicities, may explain some of the residual differences in 1910. In a separate analysis based on the 1910 IPUMS samples (not shown), we confirmed higher child mortality among French-Canadians relative to English-speaking Canadians and lower child mortality among the Jewish population from Russia and other Europe countries relative to non-Jews. In the complete model with fixed effects (M3), French-Canadians suffered a 13.8 percent disadvantage in child mortality relative to the NWNP population, compared to a 1.7 percent disadvantage among all other Canadians, all else being equal. Russian immigrants experienced 13.2 percent lower child mortality than NWNP, but Russian Jews enjoyed a 45.5 percent advantage while other European Jews enjoyed a 53.4 percent advantage, all else being equal.

The results of the fully controlled models indicate that the assimilation process was typically associated with narrowing differentials in child mortality, supportive of classic assimilation theory. The much lower differential between NWNP and Mexicans in 1900 and 1910 in the fully controlled models, for example, indicates that the assimilation process was associated with significant declines in infant mortality. Likewise, the large child mortality differential between Italians and NWNP not only declined to the point of being statistically insignificant in the full model for 1900, it reversed in 1910, with Italians enjoying a relative advantage in child mortality, all else being equal. Historians have long noted that Italians, as a newer immigrant group whose Catholicism increased their social distance from mainstream Protestant whites, experienced significant segregation and discrimination (Lieberson 1980; Pagnini and Morgan 1990; White et al. 1994). To the extent that the decline in child mortality differentials between Italians and NWNP and Mexicans and NWNP reflected the inclusion of assimilation variables in the full models, the results support classic rather than segmented immigration theory. Italians and Mexicans did not negatively assimilate with respect to child mortality.

The results for the Russian/Jewish group, by contrast, provides modest support for segmented assimilation. Jews were among the most endogamous groups with respects to marriage in the twentieth century (Dribe et al. 2018; Pagnini and Morgan 1990) and their continued mortality advantage in the American environment and their more substantial advantage in the fully controlled models suggests a type of "selective acculturation," with little change in behaviors that might have affected child mortality. The increase in mortality between 1900 and 1910 
Table 6. Estimates of contextual factors on child mortality (weighted OLS). Sample: 1G, 1.5G, $2 \mathrm{G}$

\begin{tabular}{|c|c|c|c|c|c|c|c|c|}
\hline \multicolumn{9}{|l|}{ A. 1900} \\
\hline & \multicolumn{2}{|c|}{$\begin{array}{l}\text { Relative group } \\
\text { size }\end{array}$} & \multicolumn{2}{|c|}{$\begin{array}{l}\text { Proportion } \\
\text { NWNP }\end{array}$} & \multicolumn{2}{|c|}{$\begin{array}{c}\text { Mortality } \\
\text { index (NWNP) }\end{array}$} & \multicolumn{2}{|c|}{ Diversity index } \\
\hline & Coef. & $P>t$ & Coef. & $P>t$ & Coef. & $P>t$ & Coef. & $P>t$ \\
\hline Main effects & 1.079 & 0.000 & 0.092 & 0.000 & 0.638 & 0.000 & 0.175 & 0.000 \\
\hline \multicolumn{9}{|l|}{ Interaction models } \\
\hline High mortality (ref.cat.) & 1.333 & 0.000 & 0.002 & 0.949 & 0.773 & 0.000 & 0.179 & 0.001 \\
\hline Low mortality & 0.796 & 0.001 & 0.151 & 0.000 & 0.540 & 0.000 & 0.172 & 0.913 \\
\hline \multicolumn{9}{|l|}{ B. 1910} \\
\hline & \multicolumn{2}{|c|}{$\begin{array}{l}\text { Relative group } \\
\text { size }\end{array}$} & \multicolumn{2}{|c|}{$\begin{array}{l}\text { Proportion } \\
\text { NWNP }\end{array}$} & \multicolumn{2}{|c|}{$\begin{array}{c}\text { Mortality } \\
\text { index (NWNP) }\end{array}$} & \multicolumn{2}{|c|}{$\begin{array}{l}\text { Diversity } \\
\text { index }\end{array}$} \\
\hline & Coef. & $P>t$ & Coef. & $P>t$ & Coef. & $P>t$ & Coef. & $P>t$ \\
\hline Main effects & 0.849 & 0.000 & 0.018 & 0.679 & 0.529 & 0.000 & 0.114 & 0.067 \\
\hline \multicolumn{9}{|l|}{ Interaction models } \\
\hline High mortality (ref. cat.) & 1.461 & 0.000 & -0.098 & 0.120 & 0.577 & 0.000 & 0.142 & 0.118 \\
\hline Low Mortality & -1.352 & 0.000 & 0.092 & 0.007 & 0.496 & 0.381 & 0.098 & 0.657 \\
\hline
\end{tabular}

Note: Models controls for the same variables as in M3, table 5 except ethnic origin. Each model also controls for the other contextual variables.

In the interaction models, high mortality is the reference category and p-values in this category refer to base estimates for the contextual variables. Coefficients for low mortality are net estimates (base estimate + interaction estimate) and $\mathrm{p}$-values refer to the interaction estimates, testing if the difference to the base estimate is statistically significant.

High mortality groups ( $>10 \%$ above mean): Canada, Ireland, Italy, Mexico, Hungary.

Low mortality groups ( $<10 \%$ below mean): Germany, Denmark, Norway, Sweden, the Netherlands, Russia.

Not included groups (within +/- 10\% from mean): Britain, Austria, France.

(noted in table 3), while other groups were experiencing declines, however, suggests that the Russian/Jewish population may have experienced some negative assimilation toward the NWNP.

\section{Contextual Factors}

Table 6 shows results for estimations of the contextual factors, overall for the full sample of immigrants $(1 \mathrm{G}, 1.5 \mathrm{G}$, and $2 \mathrm{G}$ ) and by mortality level in a separate interaction model for the high- and low-mortality groups. High-mortality groups are those with a mortality index 10 percent or more above the mean (Canada, Ireland, Italy, Mexico, and Hungary) and low-mortality groups are those with a mortality index lower than 10 percent below the mean (Germany, Denmark, Norway, Sweden, the Netherlands, and Russia). We excluded three nativity groups with levels close to the mean from this analysis (Britain, France, and Austria). Relative group size shows a positive association with mortality in both 1900 and 1910, implying that a higher proportion of one's own nativity group in the county of residence was associated with higher mortality. More co-natives in the area likely meant fewer interactions with the native population or other immigrant groups, 
which may have slowed down the diffusion of knowledge and adoption of behaviors promoting infant health (Easterlin 1999). It is also likely that living conditions in terms of crowding and poor housing were worse in immigrant-dense areas (enclaves), which is unobserved in our data and therefore not fully controlled for in our county fixed-effects models. The interaction models show that the association was strongest for high-mortality groups in both 1900 and 1910, and for lowmortality groups the association was negative in 1910. This implies that families from high-mortality groups living in counties with a higher proportion co-natives suffered considerably higher child mortality than similar families in counties with a lower share of co-natives. This did not change much between 1900 and 1910. For families from low-mortality groups, however, a higher share of co-natives was associated with lower child mortality in 1910.

The proportion NWNP in the county of residence was positively associated with child mortality in 1900, while there was no statistically significant association in 1910. The interaction model for 1900 shows that it was only the families from low-mortality groups that experienced the positive association, while this was not the case for those who came from high-mortality origins. In 1910, the association was much weaker than in 1900. This finding is consistent with classic assimilation theory and suggests that child mortality converged to the native white pattern. Exposure to natives implied a social learning process through which different behavior and attitudes-both good and bad-spread from the majority native group to the minority groups. In the contemporary context convergence in adult health and mortality is related to lifestyle factors such as smoking, diet, and exercise, while in the context of early-twentiethcentury child health we expect it to have been connected to health behaviors and child care such as hygiene and breastfeeding habits.

The county-level mortality index was positively associated with individual-level child mortality in both years. A one-unit higher mortality index in the county of residence increased the individual-level mortality index by about $0.5-0.6$, which was a sizeable magnitude. The associations were a bit stronger for families from high-mortality origins than for those from low-mortality origins, although this difference shrank between 1900 and 1910. Clearly, where one lived was a critical factor affecting children's chances of survival. High mortality in the county could reflect an adverse disease environment with endemic diseases. It could also reflect poor sanitation and water quality affecting mortality for large parts of the population. In addition, a county with a high-mortality index could indicate late adoption of new knowledge and practices promoting child health. These results point to an important role played by the community in which people lived, in addition to factors at the individual and family level. This again suggests that knowledge, attitudes, and behaviors were crucial contextual factors. Community factors such as sanitation, clean water, and the disease environment should have affected different immigrant groups in similar ways, unless there was a very strong segregation within counties by which immigrants from high-mortality groups lived in areas where sanitation, water and the disease environment were much worse than the areas where immigrants from low-mortality groups resided. Although we believe this was likely true in some specific cases (see, e.g., Villarreal et al. 2014), there is no evidence that such a pattern was common across the United States. We do not expect our overall results to be systematically biased, especially after including within county controls for urban/rural residence and size of city. 
The degree of diversity of the foreign-born population, as measured by the diversity index, was positively associated with child mortality. The association was weaker in 1910 than in 1900 , and not statistically significant $(\mathrm{p}=0.067)$. It was similar for families from high- and low-mortality origins. Apparently, living in a county with a more diverse immigrant population was associated with higher child mortality, net of the proportion natives, the mortality level, and the relative group size.

\section{Generation, Intermarriage, and Time in the United States}

Table 7 shows regression estimates for immigrant generation and intermarriage using only the sample of immigrants and their second-generation descendants $(1 \mathrm{G}, 1.5 \mathrm{G}$, and $2 \mathrm{G}$ ). Generation should not be equated too readily with assimilation-which is more accurately reflected in immigrants' ability to speak English, literacy, socioeconomic status, and residence patterns - but it likely captured aspects of assimilation not correlated with the assimilation variables in our models. Compared to the first generation $(1 \mathrm{G})$, the $1.5 \mathrm{G}$ (foreign born who came as children) experienced somewhat lower mortality in 1900 . For the second generation $(2 \mathrm{G})$ the difference was considerably larger. When adding controls for assimilation and place of residence in the full model most of this mortality advantage disappeared, and when also adding the county-level fixed effects the association was no longer statistically significant. Unsurprisingly, the mortality advantage for the second generation was explained by their greater degree of integration into US society in terms of language, place of residence, and socioeconomic status. This pattern did not change in 1910.

The association with exogamy was also highly similar in 1900 and 1910. Children born to women married endogamously with a second-generation immigrant had a clear mortality advantage compared to those born to women endogamously married with a first-generation immigrant. The picture was similar for intermarriage with native whites of native parentage, while the associations were a bit weaker for other exogamy. The mortality advantage associated with intermarriage declined substantially in the full model, and further in the fixed-effects model. These results again demonstrate that assimilation was important for child mortality. It was not generation or intermarriage per se that affected mortality, but they were powerful indicators of assimilation among immigrants in early-twentieth-century United States.

We also looked at associations between child mortality and generation and intermarriage separately for high- and low-mortality groups using interaction models. Table 8 shows the net effects of these models. The difference in mortality between immigrant generations was again much larger for immigrants in high-mortality groups than for those in low-mortality groups. ${ }^{6}$ Similarly, the negative association between intermarriage and child mortality was much stronger for immigrants from

\footnotetext{
${ }^{6}$ In their study of the 1910 IPUMS Hispanic oversample, Gutmann et al. (2000) reported higher second-, third-, and later-generation child mortality among the Hispanic population in some areas, particularly the population living in New Mexico. They associated this unique pattern with the poor living conditions among the Hispano population long resident of the state, a population distinct from more recent Mexican immigrants to New Mexico and to most other states. Because we relied on nativity rather than Hispanic surname to identify Mexican immigrants, we were unable to examine these differentials (most Hispano mothers in New Mexico will be categorized as NWNP in our data). Their results are consistent, however, with the high level of infant and child mortality in the NWNP population of New Mexico shown in figures 1 and 2.
} 
Table 7. Regression estimates, immigrant generations and intermarriage (weighted OLS). Sample: $1 G$, $1.5 \mathrm{G}, 2 \mathrm{G}$

\begin{tabular}{|c|c|c|c|c|c|c|c|c|}
\hline \multicolumn{9}{|l|}{ A. 1900} \\
\hline & \multicolumn{2}{|c|}{ M1 } & \multicolumn{2}{|c|}{ M1 } & \multicolumn{2}{|c|}{ M2 (Full) } & \multicolumn{2}{|c|}{ M3 (FE) } \\
\hline & Coef & $P>t$ & Coef & $P>t$ & Coef & $P>t$ & Coef & $P>t$ \\
\hline \multicolumn{9}{|c|}{ Immigrant generation } \\
\hline $1 G$ & ref & ref & & & ref & ref & ref & ref \\
\hline $1.5 \mathrm{G}$ & -0.039 & 0.002 & & & -0.033 & 0.008 & -0.021 & 0.095 \\
\hline $2 \mathrm{G}$ & -0.135 & 0.000 & & & -0.033 & 0.001 & -0.010 & 0.305 \\
\hline \multicolumn{9}{|l|}{ Intermarriage } \\
\hline 1G Endogamy & & & ref & ref & ref & ref & ref & ref \\
\hline 2G Endogamy & & & -0.119 & 0.000 & -0.021 & 0.059 & -0.020 & 0.075 \\
\hline NWNP Exogamy & & & -0.176 & 0.000 & 0.030 & 0.009 & 0.038 & 0.002 \\
\hline 2G Exogamy & & & -0.081 & 0.000 & 0.033 & 0.015 & 0.046 & 0.001 \\
\hline Other Exogamy & & & -0.021 & 0.155 & 0.024 & 0.086 & 0.029 & 0.043 \\
\hline \multicolumn{9}{|l|}{ B. 1910} \\
\hline & \multicolumn{2}{|c|}{ M1 } & \multicolumn{2}{|c|}{ M1 } & \multicolumn{2}{|c|}{ M2 (Full) } & \multicolumn{2}{|c|}{ M3 (FE) } \\
\hline & Coef & $P>t$ & Coef & $P>t$ & Coef & $P>t$ & Coef & $P>t$ \\
\hline \multicolumn{9}{|c|}{ Immigrant generation } \\
\hline $1 G$ & ref & ref & & & ref & ref & ref & ref \\
\hline $1.5 \mathrm{G}$ & -0.013 & 0.529 & & & 0.001 & 0.976 & 0.029 & 0.145 \\
\hline $2 \mathrm{G}$ & -0.115 & 0.000 & & & -0.007 & 0.685 & 0.021 & 0.212 \\
\hline \multicolumn{9}{|l|}{ Intermarriage } \\
\hline 1G Endogamy & & & ref & ref & ref & ref & ref & ref \\
\hline 2G Endogamy & & & -0.123 & 0.000 & -0.020 & 0.267 & -0.010 & 0.605 \\
\hline NWNP Exogamy & & & -0.129 & 0.000 & 0.028 & 0.146 & 0.043 & 0.034 \\
\hline 2G Exogamy & & & -0.111 & 0.000 & 0.004 & 0.862 & 0.020 & 0.337 \\
\hline Other Exogamy & & & -0.018 & 0.429 & 0.032 & 0.160 & 0.034 & 0.144 \\
\hline
\end{tabular}

Controls:

M1: Age, age squared, mortality reference date, nativity/ethnic origin.

M2: M1 + Place of residence, English speaker, spouse English speaker, literate, spouse literate, occupation score, employed, farm residence, children ever Born.

M3: M2 + county fixed effects.

Source: See table 1.

high-mortality groups. These results further support the conclusion that immigrant societal integration was of vital importance, not only in terms of finding a job and a living wage but also in terms of health and well-being.

Finally, in table 9, we studied the extent to which the time spent in the United States before getting married was associated with child mortality. The analysis is 
Table 8. Net estimates from interaction models (weighted OLS). Immigrant generation and intermarriage

\begin{tabular}{|c|c|c|c|c|}
\hline \multicolumn{5}{|l|}{ A. 1900} \\
\hline & \multicolumn{2}{|c|}{ Low Mortality } & \multicolumn{2}{|c|}{ High Mortality } \\
\hline & Coef. & $P>t$ & Coef. & $P>t$ \\
\hline \multicolumn{5}{|c|}{ Immigrant generation } \\
\hline $1 G$ & ref & ref & ref & ref \\
\hline $1.5 \mathrm{G}$ & -0.356 & 0.043 & -0.003 & 0.885 \\
\hline $2 \mathrm{G}$ & -0.199 & 0.000 & -0.148 & 0.000 \\
\hline \multicolumn{5}{|l|}{ Intermarriage } \\
\hline 1G Endogamy & ref & ref & ref & ref \\
\hline 2G Endogamy & -0.274 & 0.003 & -0.133 & 0.000 \\
\hline NWNP Exogamy & -0.137 & 0.000 & -0.271 & 0.000 \\
\hline 2G Exogamy & -0.169 & 0.000 & -0.174 & 0.000 \\
\hline Other Exogamy & -0.190 & 0.000 & -0.118 & 0.000 \\
\hline \multicolumn{5}{|l|}{ B. 1910} \\
\hline & \multicolumn{2}{|c|}{ Low Mortality } & \multicolumn{2}{|c|}{ High Mortality } \\
\hline & Coef. & $P>t$ & Coef. & $P>t$ \\
\hline \multicolumn{5}{|c|}{ Immigrant generation } \\
\hline $1 \mathrm{G}$ & ref & ref & ref & ref \\
\hline $1.5 \mathrm{G}$ & -0.262 & 0.808 & 0.011 & 0.770 \\
\hline $2 \mathrm{G}$ & -0.219 & 0.078 & -0.127 & 0.000 \\
\hline \multicolumn{5}{|l|}{ Intermarriage } \\
\hline 1G Endogamy & ref & ref & ref & ref \\
\hline 2G Endogamy & -0.216 & 0.003 & -0.174 & 0.000 \\
\hline NWNP Exogamy & -0.180 & 0.000 & -0.203 & 0.000 \\
\hline 2G Exogamy & -0.164 & 0.000 & -0.210 & 0.000 \\
\hline Other Exogamy & -0.177 & 0.004 & -0.113 & 0.006 \\
\hline
\end{tabular}

Note: Based separate regressions for generation and intermarriage. Models controls for the same variables as in model M1 (age, age squared, and MRD). High mortality is the reference category and $p$-values in this category refer to base estimates for generation/intermarriage. Coefficients for low mortality are net estimates (base estimate + interaction estimate) and p-values refer to the interaction estimates, testing if the difference to the base estimate is statistically significant.

based on a subsample of the study population limited to foreign-born women arriving as adults (1G). Having spent 5-9 years in the United States before marrying and having children reduced child mortality by about $0.05-0.06$, which provides additional evidence that improved child survival was related to assimilation. Few of the coefficients for the longer times in the United States were statistically significant, however, and it is difficult to identify a consistent pattern. One reason for this result 
Table 9. Regression estimates, time in the United States before marriage (weighted OLS). Sample: $1 G$

\begin{tabular}{|c|c|c|c|c|c|c|}
\hline \multicolumn{7}{|l|}{ A. 1900} \\
\hline & \multicolumn{2}{|c|}{ M1 } & \multicolumn{2}{|c|}{ M2 } & \multicolumn{2}{|c|}{ M3 (FE) } \\
\hline & Coef & $P>t$ & Coef & $P>t$ & Coef & $P>t$ \\
\hline $0-4$ years & ref & ref & ref & ref & ref & ref \\
\hline $5-9$ years & -0.056 & 0.000 & 0.011 & 0.471 & 0.005 & 0.759 \\
\hline $10-14$ years & -0.037 & 0.191 & 0.130 & 0.000 & 0.128 & 0.000 \\
\hline $15-19$ years & 0.114 & 0.043 & 0.293 & 0.000 & 0.269 & 0.000 \\
\hline $20-24$ years & 0.138 & 0.252 & 0.251 & 0.025 & 0.250 & 0.021 \\
\hline \multicolumn{7}{|l|}{ B. 1910} \\
\hline & \multicolumn{2}{|c|}{ M1 } & \multicolumn{2}{|c|}{ M2 } & \multicolumn{2}{|c|}{ M3 (FE) } \\
\hline & Coef & $P>t$ & Coef & $P>t$ & Coef & $P>t$ \\
\hline $0-4$ years & ref & ref & ref & ref & ref & ref \\
\hline $5-9$ years & -0.059 & 0.019 & -0.002 & 0.931 & -0.015 & 0.565 \\
\hline $10-14$ years & -0.048 & 0.235 & 0.110 & 0.005 & 0.110 & 0.008 \\
\hline $15-19$ years & 0.084 & 0.234 & 0.207 & 0.002 & 0.207 & 0.003 \\
\hline $20-24$ years & 0.217 & 0.088 & 0.326 & 0.008 & 0.369 & 0.003 \\
\hline
\end{tabular}

Controls:

M1: Age, age squared, mortality reference date, ethnic origin.

M2: M1 + place of residence, English speaker, spouse English speaker, literate, spouse literate, spouse occupation score, woman employed, farm residence, children ever born, intermarriage.

M3: M2 + county fixed effects.

was the likely negative selection of women spending a long time in the United States (10-20 years) before getting married. If we assume many adults who arrived were in their twenties, these women would have been in their late thirties or even early forties before getting married and having children. We would expect child mortality to be quite different for these women than for those forming a family in more typical ages.

\section{Conclusions}

Immigrant assimilation into host societies is a multifaceted process. In addition to learning the language, getting employment, and socioeconomic mobility, immigrant assimilation can also be related to intermarriage and acquisition of demographic behaviors affecting fertility and mortality. A crucial indicator of living standards is the health of children. In this study, we estimated infant and child mortality differentials across nativity groups in the late-nineteenth- and early-twentieth-century United States and compared the estimates to the native-born white population of native parentage. Our analysis demonstrated large mortality differentials across nativity groups. Immigrants from Mexico, Canada, Italy, Ireland, and Hungary had considerably higher child mortality than other groups and the NWNP, while those 
from Russia, Scandinavia, Germany, and the Netherlands had lower than average levels. Mexican immigrants, in particular, had very high rates of child mortality. There was no "Hispanic paradox" in child mortality in the early twentieth century. The pattern of ancestry differences in child mortality remained stable between 1900 and 1910, despite considerable mortality decline and continued high immigration, especially from southern Europe. After adjusting for individual-level variables capturing assimilation and residence location, however, differentials in child mortality by ancestry generally became much less pronounced. The more modest ancestry differentials in the fully controlled models indicate the importance of assimilation and residence in the observed mean differences in child mortality. One notable exception was the Russian (mostly Jewish) population, whose mortality advantage grew considerably larger after adjusting for their adverse living conditions.

Similarly, when we accounted for unobserved county-level variables, mortality differentials relative to the NWNP further diminished for most groups. These results show that while there were large mortality differences by ancestry in the United States at the turn of twentieth century, they could to a large extent be explained by other factors, such as where different groups tended to live and their socioeconomic and cultural integration into US society. Not all differences could be explained this way. After controlling for assimilation and place of residence, Mexicans had more than 16 percent higher child mortality than the NWNP in 1900 and 25 percent higher mortality in 1910. At the same time the Russian, Austrian, and Hungarian ancestry populations — each of which included substantial numbers of Jewish immigrants-enjoyed significant mortality advantages in both census years relative to NWNP in fully controlled models with county-level fixed effects. For most other groups, however, mortality differences relative to the NWNP population were 10 percent or less. We believe that the residual ancestry differences, net of measured assimilation and county context, are related to specific differences in child-caring behaviors, breastfeeding practices, hygiene, and possibly residential segregation, discrimination, and environmental conditions below the county level.

Our analysis also indicated that the context in which people lived was important for their children's risk of mortality, as measured by the association between child mortality and the proportion co-natives, the proportion NWNP, the diversity index, and the average mortality index of the NWNP in the county of residence. These contextual variables help to explain some of the nativity differentials in mortality, and were also important in their own right. Moreover, the associations differed considerably depending on the ancestry group, with the more disadvantaged groupsimmigrants from high-mortality origins-generally showing stronger contextual associations.

Finally, we demonstrated clear mortality differences between immigrant generations and by marital exogamy. Overall, second-generation immigrants, as well as first-generation immigrants intermarried with natives or second-generation immigrants, had a mortality advantage. Much of this advantage was related to the greater assimilation of the second generation and of intermarried immigrants as predicted by classic immigration theory. We find little evidence supporting segmented immigration theory among the immigrant groups studied here, at least with respects to the mortality of children. Although the persistence and widening of a mortality 
advantage among Russian immigrants in the fully controlled models suggests a possible exception for Jewish immigrants, we also observed that Russian child mortality increased between 1900 and 1910 and that the mortality advantage for children of Russian ancestry relative to the NWNP population declined in 1910. We observed no diverging patterns of infant and child mortality related to any group's marginalization in society.

Our analysis of turn of the century child mortality in the United States clearly points to societal integration of immigrants - classic assimilation theory-as crucial not only for their economic status, as has been often stressed, but also for their living standards in a broader sense. Evidently, integration at both the individual and contextual levels profoundly affected the survival of children in early-twentieth-century United States, diminishing initially large differences between different groups of different origin.

Acknowledgments. We are grateful for valuable comments from the anonymous reviewers of this journal and participants at the following meetings: Population Association of America (2016), the European Population Conference (2016), the European Society for Historical Demography (2016), and the Social Science History Association (2016). Partial funding for this study was provided by the Wallander foundation at Svenska Handelsbanken and the Centre for Economic Demography, Lund University, the Minnesota Population Center (P2C HD041023), through a grant from the Eunice Kennedy Shriver National Institute for Child Health and Human Development (NICHD), and NICHD grant 1 R01-HD082120-01.

\section{References}

Abramitzky, Ran, and Leah Boustan (2017) "Immigration in American economic history." Journal of Economic Literature 55 (4): 1311-45.

Alba, Richard D., and Reid M. Golden (1986) "Patterns of ethnic marriage in the United States." Social Forces 65 (1): 202-23.

Alba, Richard D., and Victor Nee (1997) "Rethinking assimilation theory for a new era of immigration." International Migration Review 31 (4): 826-74.

- (2003) Remaking the American Mainstream: Assimilation and Contemporary Immigration. Cambridge, MA: Harvard University Press.

Alesina, Alberto, Arnaud Devleeschauwer, William Easterly, Sergio Kurlat, and Romain Wacziarg (2003) "Fractionalization." Journal of Economic Growth 8 (2): 155-94.

Bernhardt, Eva (1995) "Overcrowding and mortality from airborne infectious disease: The case of Stockholm 1895-1925," in Anders Brändström and Lars-Göran Tedebrand, (eds.) Swedish Urban Demography during Industrialization. Umeå: The Demographic Database: 65-92.

Bhalotra, Sonia, and Samantha Rawlings (2013) "Gradients of the intergenerational transmission of health in developing countries." Review of Economics and Statistics 95 (2): 660-72.

Burström Bo, Finn Diderichsen, and Lars Smedman (1999) "Child mortality in Stockholm during 1885-1910: The impact of household size and number of children in the family on the risk of death from Measles." American Journal of Epidemiology 149 (12): 1134-41.

Burström Bo, Gloria Macassa, Lisa Öberg, Eva Bernhardt, and Lars Smedman (2005) "Equitable child health interventions: The impact of improved water and sanitation on inequalities in child mortality in Stockholm, 1878 to 1925." American Journal of Public Health 95 (2): 208-16.

Caldwell, John C. (1979) "Education as a factor in mortality decline: An examination of Nigerian data." Population Studies 33 (3): 395-413.

Caldwell, John C., and Peter McDonald (1982) "Influence of maternal education on infant and child mortality: Levels and causes." Health Policy and Education 2 (2-4): 251-67.

Carrigan, William D., and Clive Web (2013) Forgotten Dead: Mob Violence against Mexicans in the United States, 1848-1928. New York: Oxford University Press. 
Coale, Ansley J., and Paul Demeny (1966) Regional Model Life Tables and Stable Populations. Princeton, NJ: Princeton University Press.

Condran, Gretchen A., and Eileen Crimmins-Gardner (1978) "Public health measure and mortality in US cities in the late nineteenth century." Human Ecology 6 (1): 27-54

(1980) "Mortality differentials between rural and urban areas of states in the northeastern United States 1890-1900." Journal of Historical Geography 6 (2): 179-202.

Condran, Gretchen A., Henry Williams, and Rose A. Cheney (1984) "The decline in mortality in Philadelphia from 1870 to 1930: The role of municipal services." The Pennsylvania Magazine of History and Biography 108 (2): 153-77.

Connor, Dylan S. (2017) "Poverty, religious differences, and child mortality in the early twentieth century: The case of Dublin." Annals of the American Association of Geographers 107 (3): 625-46.

Cutler, David M., and Grant Miller (2005) "The role of public health improvements in health advances: The twentieth-century United States." Demography 42 (1): 1-22.

De León, Arnoldo (1982) They Called Them Greasers: Anglo Attitudes toward Mexicans in Texas, 18211900. Austin: University of Texas Press.

Derosas, Renzo (2003) "Watch out for the children: Differential infant mortality of Jews and Catholics in nineteenth-century Venice." Historical Methods 36 (3): 109-30.

Desai, Sonalde, and Soumya Alva (1998) "Maternal education and child health: Is there a strong causal relationship?” Demography 35 (1): 1-81.

Drachsler, Julius (1920) Democracy and Assimilation: The Blending of Immigrant Heritages in America. New York: Macmillan.

Dribe, Martin, J. David Hacker, and Francesco Scalone (2018) "Becoming American: How context shaped intermarriage during the great migration to the United States at the turn of the twentieth century." Journal of Interdisciplinary History 49 (2): 189-218.

Easterlin, Richard A. (1999) "How beneficent is the market? A look at the modern history of mortality." European Review of Economic History 3 (3): 257-94.

Eriksson, Katherine, Gregory T. Niemesh, and Melissa Thomasson (2018) "Revising infant mortality rates for the early 20th century United States." Demography 55 (6): 2001-24.

Ferrie, Joseph P., and Werner Troesken (2008) "Water and Chicago's mortality transition, 1850-1925." Explorations in Economic History 45 (1): 1-16.

Gabaccia, Donna R. (1984) From Sicily to Elizabeth Street: Housing and Social Change among Italian Immigrants, 1880-1930. Albany: State University of New York Press.

Gordon, Milton M. (1964) Assimilation in American Life: The Role of Race, Religion, and National Origins. New York: Oxford University Press.

Gratton, Brian, and Myron P. Gutmann (2000) "Hispanics in the United States, 1850-1990: Estimates of population size and national origin." Historical Methods: A Journal of Quantitative and Interdisciplinary History 33 (3): 137-53.

Gratton, Brian, Myron P. Gutmann, and Emily Skop (2007) "Immigrants, their children, and theories of assimilation: Family structure in the United States, 1880-1970." The History of the Family 12 (3): 203-22.

Gutmann, Myron P., Michael R. Haines, W. Parker Frisbie, and K. Stephen Blanchard (2000) "Intraethnic diversity in Hispanic child mortality, 1890-1910.” Demography 37 (4): 467-75.

Hacker, J. David, and Michael R. Haines (2005) "American Indian mortality in the late nineteenth century: The impact of federal assimilation policies on a vulnerable population." Annales de Démographie Historique 110 (2): 17-45.

Haines, Michael R. (2001) "The urban mortality transition in the United States, 1800-1940." Annales de Démographie Historique 101 (1): 33-64.

_ (2003) "Ethnic differences in demographic behavior in the United States: Has there been convergence?” Historical Methods 36 (4): 157-95.

Haines, Michael R., and Samuel H. Preston (1997) "The use of the census to estimate childhood mortality: Comparisons from the 1900 and 1910 United States Public Use Samples." Historical Methods 30 (2): 77-96.

Hummer, Robert A., Monique Biegler, Peter B. De Turk, Douglas Forbes, W. Parker Frisbie, Ying Hong, and Starling G. Pullum (1999) "Race/ethnicity, nativity, and infant mortality in the United States." Social Forces 77 (3): 1083-118. 
Hummer Robert A., Daniel A. Powers, Starling G. Pullum, Ginger L. Gossman, and W. Parker Frisbie (2007) "Paradox found (again): Infant mortality among the Mexican-origin population in the United States.” Demography 44 (3): 441-57.

Hummer, Robert A., Jennifer E. Melvin, and Monica He (2015) "Immigration: Health and mortality," in James D. Wright, (ed.) International Encyclopedia of the Social \& Behavioral Sciences. Oxford: Elsevier Press: 654-61.

Jaadla, Hannaliis, and Allan Puur (2016) "The impact of water supply and sanitation on infant mortality: Individual-level evidence from Tartu, Estonia, 1897-1900.” Population Studies 70 (2): 163-79.

Jasso, Guillermina, Douglas S. Massey, Mark R. Rosenzweig, and James P. Smith (2004) "Immigrant health: Selectivity and acculturation," in Norman B. Anderson, Rodolfo A. Bulatao, and Barney Cohen, (eds.) Critical Perspectives on Racial and Ethnic Differences in Health in Late Life. Washington, DC: National Academies Press: 227-66.

Kesztenbaum, Lionel, and Jean-Laurent Rosenthal (2017) “Sewers' diffusion and the decline of mortality: The case of Paris, 1880-1914.” Journal of Urban Economics 98 (1): 174-86.

Knodel, John, and Hallie J. Kintner (1977) "The impact of breast feeding patterns on the biometric analysis of infant mortality." Demography 14 (4): 391-409.

Landale, Nancy S., R. S. Oropesa, and Bridget K. Gorman (2000) "Migration and infant death: Assimilation or selective migration among Puerto Ricans?" American Sociological Review 65 (6): 888-909.

Lieberson, Stanley M. (1980) A Piece of the Pie: Blacks and White Immigrants since 1880. Berkeley: University of California Press.

Lieberson, Stanley M., and Mary C. Waters (1988) From Many Strands: Ethnic and Racial Groups in Contemporary America. New York: Russel Sage Foundation.

Markides, Kyriakos S., and Karl A. Eschbach (2005) "Aging, migration and mortality: Current status of research on the Hispanic paradox." Journals of Gerontology: Series B: 60B (Special Issue II): 68-75.

Marmot, M. G., A. M. Adelstein, and L. Bulusuab (1984) "Lessons from the study of immigrant mortality." Lancet 323 (8392): 1455-57.

McKeown, Thomas (1976) The Modern Rise of Population. London: Edward Arnold.

Mosley, W. Henry, and Lincoln C. Chen (1984) "An analytical framework for the study of child survival in developing countries.” Population and Development Review 10 (Suppl.): 25-45.

Olson, Sherry, and Patricia Thornton (2011) Peopling the North American City Montreal, 1840-1900. Montreal: McGill-Queen's University Press.

Pagnini, Deanna L., and S. Philip Morgan (1990) "Intermarriage and social distance among US immigrants at the turn of the century." American Journal of Sociology 96 (2): 405-32.

Palloni, Alberto, and Elizabeth Arias (2004) "Paradox lost: Explaining the Hispanic adult mortality advantage." Demography 41 (3): 385-415.

Portes, Alejandro, and Rubén G. Rumbaut (2001) Legacies: The Story of the Immigrant Second Generation. Berkeley: University of California Press.

Portes, Alejandro, and Min Zhou (1993) “The new second generation: Segmented assimilation and its variants." The Annals of the American Academy of Political and Social Science 530: 74-96.

Preston, Samuel H. (1989) Census of Population, 1910: Public Use Sample. ICPSR09166-v1. Ann Arbor, MI: Inter-university Consortium for Political and Social Research [distributor]. https://doi.org/10.3886/ ICPSR09166.v1.

Preston, Samuel H., Douglas C. Ewbank, and Mark Hereward (1994) "Child mortality differences by ethnicity and race in the United States: 1900-1910," in Susan Cotts Watkins, (ed.) After Ellis Island: Newcomers and Natives in 1910 Census. New York: Russel Sage Foundation: 35-82.

Preston, Samuel H., and Michael R. Haines (1991) Fatal Years: Child Mortality in Late NineteenthCentury America. Princeton, NJ: Princeton University Press.

Preston, Samuel H., and Robert L. Higgs (1992) United States Census Data, 1900: Public Use Sample. ICPSR07825-v1. Ann Arbor, MI: Inter-university Consortium for Political and Social Research [distributor]. https://doi.org/10.3886/ICPSR07825.v1.

Riosmena, Fernando, Rebeca Wong, and A. Palloni (2013) "Migration selection, protection, and acculturation in health: A binational perspective on older adults.” Demography 50 (3): 1039-64. 
Ruggles, Steven, Katie Genadek, Ronald Goeken, Josiah Grover, and Matthew Sobek (2015) Integrated Public Use Microdata Series: Version 6.0 [Machine-readable database]. Minneapolis: University of Minnesota.

Sandberg, Neil C. (1974) Ethnic Identity and Assimilation: The Polish-American Community. New York: Praeger.

Sassler, Sharon (2005) "Gender and ethnic differences in marital assimilation in the early twentieth century." International Migration Review 39 (3): 608-36.

Simpson, E. H. (1949) "Measurement of diversity." Nature 163: 688.

Singh, Gopal K., and Robert A. Hiatt (2006) "Trends and disparities in socioeconomic and behavioral characteristics, life expectancy, and cause-specific mortality of native-born and foreign-born populations in the United States, 1979-2003." International Journal of Epidemiology 35 (4): 903-19.

Sobek, Matthew (1995) "The comparability of occupations and the generation of income scores." Historical Methods 28 (1): 47-51.

Troesken, Werner (2004) Water, Race, and Disease. Cambridge, MA: MIT Press.

Trussell, James, and Samuel Preston (1982) "Estimating covariates of childhood mortality from retrospective reports of mothers." Health Policy and Education 3 (1): 1-36.

United Nations (1983) Indirect Techniques for Demographic Estimation: Manual X. New York: United Nations.

Van Poppel, Frans, Marianne Jonker, and Kees Mandemakers (2005) "Differential infant and child mortality in three Dutch regions, 1812-1909." Economic History Review 58 (2): 272-309.

Van Poppel, Frans, and Cor van der Heijden (1997) "The effects of water supply on infant and childhood mortality: A review of historical evidence." Health Transitions Review 7 (2): 113-48.

Viruell-Fuentes, Edna A. (2007) "Beyond acculturation: Immigration, discrimination, and health research among Mexicans in the United States." Social Science \& Medicine 65 (7): 1524-35.

Walker, Francis A. (1891) "Immigration and degradation." Forum 11: 634-44.

White, Michael J., Robert F. Dymowski, and Shilian Wang (1994) "Ethnic neighbors and ethnic myths: An examination of residential segregation in 1910," in Susan Cotts Watkins, (ed.), After Ellis Island: Newcomers and Natives in the 1910 Census. New York: Russell Sage Foundation, 175-208.

Wildsmith, Elizabeth, Myron P. Gutmann, and Brian Gratton (2003) "Assimilation and intermarriage for US immigrant groups, 1880-1990.” History of the Family 8 (4): 563-84.

Villarreal, Carlos, Brian Bettenhausen, Eric Hanss, and Jonathan Hersh (2014) "Historical health conditions in major US cities: The HUE data set." Historical Methods 47 (2): 67-80.

Woodbury, Robert M. (1925) Causal Factors in Infant Mortality: A Statistical Study Based on Investigations in Eight Cities. Washington, DC: US Department of Labor.

Woods, Robert (2000) The Demography of Victorian England and Wales. Cambridge: Cambridge University Press.

Woods, Robert, Naomi Williams, and Chris Galley (1993) "Infant mortality in England, 1550-1950," in Carlo A. Corsini and Pier Paolo Viazzo, (eds.) The Decline of Infant Mortality in Europe, 1800-1950. Four National Case Studies. Florence: UNICEF: 57-72.

Zhou, Min (1997) "Segmented assimilation: Issues, controversies, and recent research on the new second generation.” International Migration Review 31 (4): 975-1008.

Cite this article: Dribe, Martin, J. David Hacker, and Francesco Scalone (2020) "Immigration and Child Mortality: Lessons from the United States at the Turn of the Twentieth Century," Social Science History 44: 57-89. doi:10.1017/ssh.2019.42 